\title{
OBSERVING AND PREDICTING THE 20I5/16 EL NIÑO
}

\author{
Michelle L. L'Heureux, Ken Takahashi, Andrew B. Watkins, Anthony G. Barnston, Emily J. \\ Becker, Tom E. Di liberto, Felicity Gamble, Jon Gottschalck, Michael S. Halpert, Boyin Huang, \\ Kobi Mosquera-VÁsquez, and Andrew T. Wittenberg
}

The El Niño of 2015/16 rivaled the major El Niño events of 1982/83 and 1997/98, showcasing advancements in operational observing and prediction systems, while offering challenges for the future.

AfFiliations: L'HeureuX, GotTsChalck, and HalperT-NOAA/ NWS/NCEP/Climate Prediction Center, College Park, Maryland; Takahashi and Mosquera-Vásquez-Instituto Geofísico del Perú, Lima, Peru; WatKInS AND GAMble-Australian Bureau of Meteorology, Melbourne, Victoria, Australia; BARNSTON-International Research Institute for Climate and Society, Columbia University, New York, New York; BECKer AND DI LiBerTo-NOAA/ NWS/NCEP/Climate Prediction Center/Innovim, College Park, Maryland; HuANG - NOAA/National Centers for Environmental Information, Asheville, North Carolina; WITTENBERG-NOAA/ Geophysical Fluid Dynamics Laboratory, Princeton, New Jersey CORRESPONDING AUTHOR: Michelle L'Heureux, michelle.Iheureux@noaa.gov

The abstract for this article can be found in this issue, following the table of contents.

DOI:10.1175/BAMS-D-16-0009.I

A supplement to this article is available online (10.1175/BAMS-D-16-0009.2)

In final form 26 October 2016

()ㅣㄹ American Meteorological Society recent El Niño was embedded within the fabric of the Internet and social media, with arguably more frequent updates and pathways to convey information than ever before. By mid-2015, operational forecast centers around the world were nearly unanimous: this El Niño was very likely to be strong, with the potential of rivaling previous major El Niño events in 1982/83 and 1997/98. Given the widespread coverage of these ENSO outlooks and the comparisons made to other similarly strong El Niño events, there was considerable concern about significant global impacts. While the El Niño phenomenon itself was well predicted in 2015/16, climate impacts near El Niño's peak matched historical patterns in some areas (e.g., Ropelewski and Halpert 1987; Halpert and Ropelewski 1992), but in other regions, additional climate factors clearly played a role.

Because the ENSO cycle, with its warm (El Niño) and cool (La Niña) phases, is a leading source of seasonal climate variability and predictability, it is closely monitored by many national and international organizations. The authorship on this paper is composed of individuals associated with three nationallevel assessments on ENSO from the National Oceanic and Atmospheric Administration (NOAA) in the United States, the Bureau of Meteorology (BoM) in Australia, and one of the agencies that composes the 
Multisectoral Committee of the National Study of El Niño (ENFEN) in Peru. All provide operational, or regularly updated, ENSO assessments, in part because these countries are known to have climates-and indeed economies and societies-significantly influenced by ENSO. These three agencies also happen to be geographically complementary, spanning the Pacific Ocean basin. They go beyond the automatic generation of observational and model output to provide summary-level information of the progress of ENSO and its forecast, which is aimed at a diverse set of users among the general public, whose knowledge ranges from technically savvy to novice.

ENSO is a sprawling and multifaceted coupled ocean-atmosphere climate phenomenon that affects every country in a different manner. Table 1 summarizes the current El Niño definitions and watch/alert/ warning systems in association with the national-level ENSO updates. As in past years, the timing of El Niño status updates and declarations varied during 2015/16 because of differences in datasets and ENSO criteria and thresholds, which are governed by differing regional impacts. For example, Peru issues forecasts for a "coastal El Niño" because the amount of coastal rainfall they receive is very sensitive to how warm sea surface temperatures (SST) adjacent to South America become (e.g., Takahashi 2004). Ultimately, though, every agency examines a broad range of oceanic and atmospheric anomalies to inform their updates. Internationally, the Niño-3.4 SST region (thin red box in Fig. 6), in the east-central equatorial Pacific Ocean, is perhaps the most common measure of ENSO because this region is strongly coupled with the overlying atmosphere (e.g., Barnston et al. 1997) and to global teleconnections. This index also tends to be the focus of operational model displays.

These operational updates have evolved over past decades as a result of lessons learned from previous ENSO events and user demands placed on them. The 2015/16 El Niño not only showcased the latest generation of ENSO climate services, but this knowledge was disseminated and interpreted across a wide variety of media platforms, ranging from traditional mainstream outlets to social media-a vastly different communication environment compared to the last major El Niño event of 1997/98. This came with its own set of advantages, such as exposure to far broader audiences, and disadvantages, such as the sometimesquestionable interpretation of datasets and forecast outlooks, which differed from official assessments. While the ENSO assessments and dissemination processes vary by national agency, the following sections of this paper summarize our collective experience in tracking the observational evolution, verifying the model forecasts, and documenting the global climate anomalies associated with the historic 2015/16 El Niño.

DATASETS AND METHODS. Since the major El Niño of 1997/98, many observational reconstructions and reanalysis datasets have been created or improved. Unlike station-based data or point "in situ" observations (e.g., a buoy), these gridded datasets are complete both spatially and temporally and, for the statistical reconstructions of SST, extend as far back as the late 1800s. Several operationally oriented centers update datasets in near-real time, which allows scientists to monitor the tropical Pacific. Given the interest in the 2015/16 El Niño and its potential impacts, these real-time datasets were popular with users, many of whom were interested in the strength of the event and its ranking relative to past El Niño events.

Complicating this assessment, however, each center relies on a set of core observational datasets for its ENSO updates, so the exact values for a given variable (e.g., Niño-3.4 SST) will vary depending on which dataset is examined. These differences between datasets primarily arise because of structural reasons, such as the choice of the dynamical model or the statistical method used to infill between available observations. The disparities are particularly evident across the tropical Pacific Ocean, which contains large regions that are not covered by point measurements (e.g., buoys, ships). Many centers additionally rely on datasets that ingest not only buoy or ship data, but also satellite information. However, the modern satellite record began in the late 1970s, which prevents the use of these datasets for historical rankings going further back in time. Moreover, satellite estimates have biases (due to issues like varying equatorial crossing times), which need to be corrected by in situ surface observations, and these corrections can vary over time and space as new satellites are incorporated (e.g., Huang et al. 2015a). Some datasets like the NOAA Extended Reconstructed SST (ERSST) opt to not include satellite information in order to preserve the consistency, or homogeneity, of the record. But, for purposes outside of historical comparisons and to provide more real-time ENSO updates, these satellitebased datasets are strongly relied upon both to get an overall sense of the ENSO evolution and as the initial conditions for many forecast models.

Because of the interest in how the 2015/16 event compares with other major El Niño events, we prioritize datasets that are routinely updated and, when possible, datasets that were constructed with the 
intent of providing a consistent, homogenous climate record. Individually, none of these datasets represent "the truth" or perfect measurements over the entire tropical Pacific Ocean. For that reason, in addition to showing the individual datasets, we also display the average of multiple datasets to compare events, which we hypothesize can reduce the structural error associated with the observational datasets, analogous to the reduction of error through multimodel averaging (e.g., DelSole et al. 2014).

To compare historical strength, we focus on the SST statistical reconstructions: two versions of ERSST (v3b and v4; Smith et al. 2008; Huang et al. 2015b), the Hadley Centre SST (HadISST; Rayner et al. 2003), and the Centennial In Situ Observation-Based Estimates (COBE) SST dataset (Ishii et al. 2005), which extend back to the late 1800s. All Niño index regions (shown in Fig. 6) are computed to provide a sense of how the events varied by location. These indices span the equatorial Pacific Ocean and are used to summarize the breadth of the SST anomalies and where they are largest. Thus, these regions are also used to provide information on the "El Niño flavor," a term popularized in recent years to describe the continuum of different spatial patterns of SST anomalies that result from ENSO (Capotondi et al. 2015).

To evaluate the tropical Pacific atmosphere, we feature the zonal gradient of $1000-\mathrm{hPa}$ geopotential height between Indonesia and the eastern equatorial Pacific, the equatorial Southern Oscillation index (EQSOI), and the more traditional, station-based Tahiti minus Darwin Southern Oscillation index (SOI). To compare the former, we use seven reanalysis datasets that extend back to at least 1979 (see caption of Fig. 5). We also examine three satellite-based outgoing longwave radiation (OLR) records, a proxy for tropical convection, which compared to precipitation, is better monitored over the tropical Pacific Ocean and therefore more stable in time and space. Data are based on the Advanced Very High Resolution Radiometer (AVHRR; Liebmann and Smith 1996) and the High Resolution Infrared Radiation Sounder (HIRS) v2r2 and v2r7 (Lee et al. 2007).

To describe the within-event evolution of the 2015/16 El Niño and how similar it was to past major events, we make use of the daily depth of the $20^{\circ} \mathrm{C}$
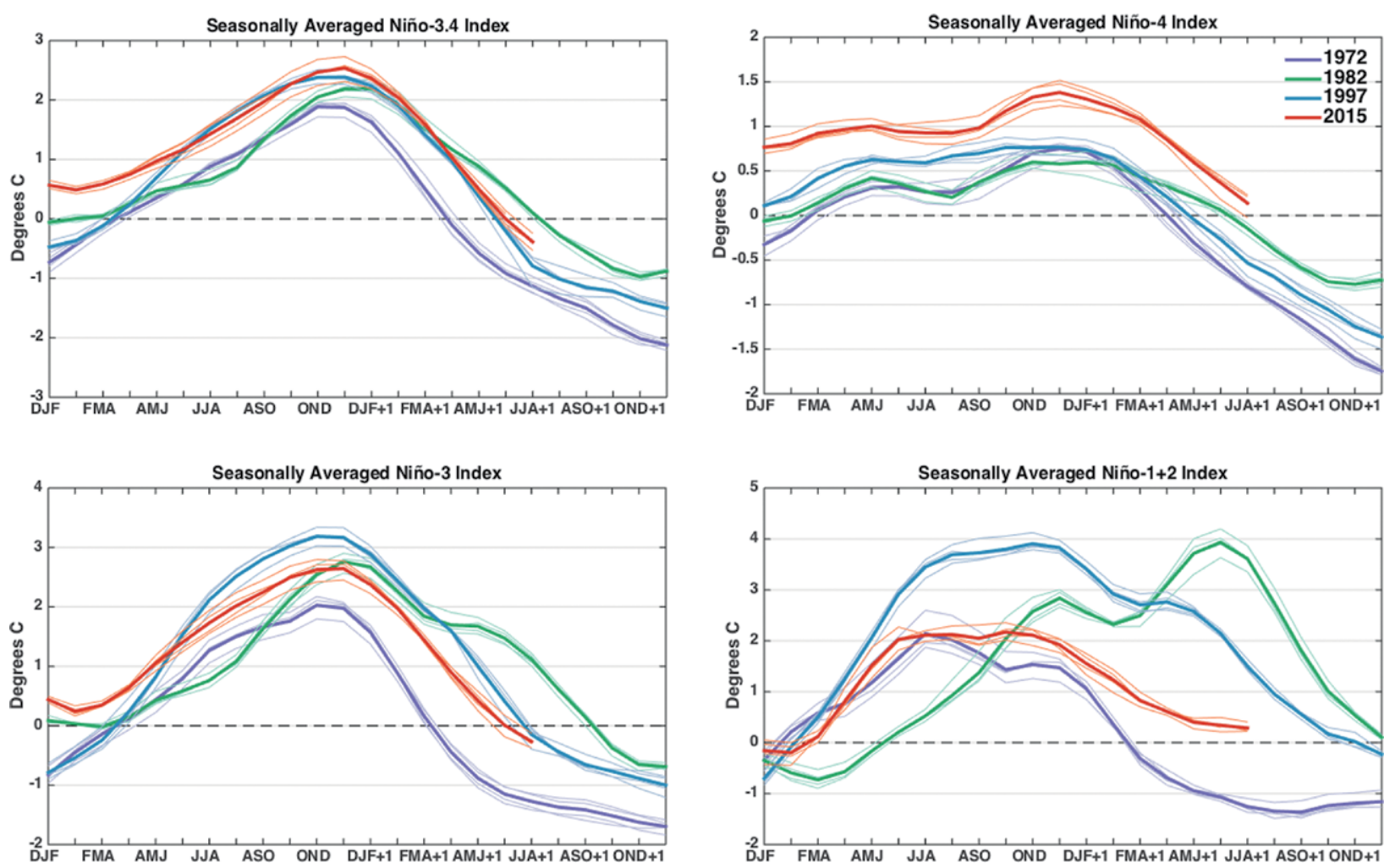

Fig. I. Evolution of seasonal (3 month) averaged values of the (top left) Niño-3.4, (top right) Niño-4, (bottom left) Niño-3, and (bottom right) Niño-I+2 SST indices during 2015/16 (red), 1997/98 (blue), $1982 / 83$ (green), and I972/73 (purple). The Niño-3.4 region covers $5^{\circ} \mathrm{N}-5^{\circ} \mathrm{S}, 170^{\circ}-120^{\circ} \mathrm{W}$; the Niño-4 region covers $5^{\circ} \mathrm{N}-5^{\circ} \mathrm{S}, 150^{\circ}-160^{\circ} \mathrm{E}$; the Niño-3 region covers $5^{\circ} \mathrm{N}-5^{\circ} \mathrm{S}, 150^{\circ}-90^{\circ} \mathrm{W}$; and the Niño- $1+2$ region covers $0^{\circ}-10^{\circ} \mathrm{S}, 90^{\circ}-80^{\circ} \mathrm{W}$ (regions displayed in Fig. 6). Thin lines correspond to the ERSSTv3b, ERSSTv4, COBE, and HadISST datasets and the thicker line is the average of all datasets. Departures are formed by removing monthly means during 198I-2010. 
TABLE I. Current ENSO systems for Australia, Peru, and the United States.

\section{Australian Bureau of Meteorology}

El Niño/La Niña watch: The chance of an El Niño developing in the coming season has increased. When these criteria have been met in the past, El Niño/La Niña conditions have developed around $50 \%$ of the time. The following criteria are used:

I) ENSO phase is currently neutral or La Niña/El Niño is declining.

2) Either of the following conditions apply: of the closest 20 analog years (based on SOI), 4 or more have shown El Niño/La Niña characteristics or significant subsurface warming (EI Niño) or cooling (La Niña) has been observed in the western or central equatorial Pacific Ocean.

3) One-third or more of the surveyed climate models show SSTs at least $0.8^{\circ} \mathrm{C}$ above average (El Niño) or below average (La Niña) in the Niño-3 or Niño-3.4 regions by late winter or spring.

El Niño/La Niña alert: The chance of an El Niño/La Niña developing in the coming season has increased. When these criteria have been met in the past, EI Niño/La Niña has developed around $70 \%$ of the time. The following three criteria need to be met: I) A clear warming (EI Niño) or cooling (La Niña) trend has been observed in the Niño-3 or Niño-3.4 regions during the past 3-6 months.

2) Trade winds have been weaker (El Niño) or stronger (La Niña) than average in the western or central equatorial Pacific Ocean during any 2 of the last 3 months.

3) The 2-month average $\mathrm{SOI}$ is -7 or lower (El Niño) or +7 or higher (La Niña).

4) A majority of surveyed climate models show SSTs at least $0.8^{\circ} \mathrm{C}$ above average (El Niño) or below average (La Niña) in the Niño-3 or Niño-3.4 regions by the late winter or spring.

El Niño/La Niña: An El Niño/La Niña has been declared and is under way. Any three of the following criteria need to be met:

1) Temperatures in the Niño-3 or Niño-3.4 regions are $0.8^{\circ} \mathrm{C}$ warmer (El Niño) or cooler (La Niña) than average.

2) Trade winds have been weaker (El Niño) or stronger (La Niña) than average in the western or central equatorial Pacific Ocean during any 3 of the last 4 months.

3) The 3-month average SOI is -7 or lower (EI Niño) or +7 or higher (La Niña).

4) A majority of surveyed climate models show SSTs remaining at least $0.8^{\circ} \mathrm{C}$ above average (EI Niño) or below average (La Niña) in the Niño-3 or Niño-3.4 regions of the Pacific until the end of the year.

Updated as part of the ENSO Wrap-Up: www.bom.gov.au/climate/enso/

\section{Comité encargado del Estudio Nacional del Fenómeno EI Niño (ENFEN Committee, Peru)}

ENFEN monitors and predicts El Niño/La Niña in two regions:

- The first is the "coastal" El Niño (La Niña), when the Índice Costero El Niño (ICEN; 3-month running-mean Niño-I+2 SST index, www.met.igp.gob.pe/datos/icen.txt) is above (below) $0.4^{\circ} \mathrm{C}\left(-1.0^{\circ} \mathrm{C}\right)$ for three or more consecutive months.

The overall strength of the event is determined by the three largest ICEN values in the event, according to preestablished thresholds. In the Northern Hemisphere winter/spring, warming can produce heavy rain over the arid coast.

- The second region is the "central Pacific" El Niño/La Niña, which is based on the Niño-3.4 SST index using a threshold of $\pm 0.5^{\circ} \mathrm{C}$. This impacts the Peruvian Andes and the Amazon through teleconnections.

The following are the alert system states for the coastal El Niño/La Niña:

- Coastal El Niño/La Niña watch, when there is a higher expectation that El Niño/La Niña will occur than not.

- Coastal EI Niño/La Niña alert, when the El Niño/La Niña is believed to have started based on observed ocean-atmosphere conditions and/or if the ICEN qualifies.

- Inactive, when neutral conditions are present or El Niño/La Niña conditions are expected to end.

Updated as part of ENFEN's official statements: www.imarpe.pe/imarpe/lista.php?id_seccion=10 $\mid 66020000000000000000$

isotherm from the Tropical Atmosphere Ocean (TAO; McPhaden et al. 2010) buoys and Argo floats (e.g., Roemmich and Gilson 2009), weekly SST results from the Optimal Interpolation SST dataset (OISSTv2; Reynolds et al. 2002), and daily 10-m winds from the European Centre for Medium-Range Weather Forecasts (ECMWF) interim reanalysis (ERA-Interim) (Dee et al. 2011). To evaluate the combined multimodel forecasts made by the International Research Institute for Climate and Society (IRI) and Climate Prediction Center (CPC) during 2014-16, the newer, higher-resolution $\left(0.25^{\circ} \times 0.25^{\circ}\right)$ daily OISST product is used to compute seasonal mean Niño-3.4 index values (Reynolds et al. 2007). While most models are not initialized with the same SST data, the dynamical models use higher-resolution analyses like the daily OISST.

To examine the 500-hPa geopotential height anomalies over the globe during the Northern Hemisphere winter, we make use of monthly data from the National Centers for Environmental Prediction (NCEP)-National Center for Atmospheric Research (NCAR) reanalysis (Kalnay et al. 1996). Observed surface air temperature data are obtained from the $2.5^{\circ} \times 2.5^{\circ}$ gridded GHCN+CAMS temperature dataset (Fan and Van den Dool 2008), a combination 
TABle I. Continued.

National Oceanic and Atmospheric Administration (NOAA)/Climate Prediction Center, United States

El Niño/La Niña watch: When oceanic and atmospheric conditions across the tropical Pacific are favorable for the onset of El Niño-La Niña within the next 6 months.

El Niño/La Niña advisory, when El Niño/La Niña conditions are present as measured by the following three criteria:

El Niño advisory:

I) I-month Niño-3.4 SST index value that is at or in excess of $+0.5^{\circ} \mathrm{C}$,

2) atmospheric conditions are consistent with EI Niño (i.e., weaker low-level trade winds, enhanced convection over the central or eastern Pacific Ocean), and

3) The expectation that El Niño will persist as measured by at least five overlapping seasonal (3-month average) Niño-3.4 SST index values at or in excess of $+0.5^{\circ} \mathrm{C}$.

La Niña advisory:

I) I-month Niño-3.4 SST index value that is equal to or less than $-0.5^{\circ} \mathrm{C}$,

2) atmospheric conditions are consistent with La Niña (i.e., stronger low-level trade winds, suppressed convection over the central Pacific Ocean), and

3) the expectation that La Niña will persist as measured by at least five overlapping seasonal (3-month average) Niño-3.4 SST index values at or less than $-0.5^{\circ} \mathrm{C}$.

Final El Niño/La Niña advisory, when the El Niño/La Niña has ended.

Not active (NA), when the ENSO alert system is not active.

Updated as part of the ENSO Diagnostics Discussion: www.cpc.ncep.noaa.gov/products/analysis_monitoring/enso advisory/index.shtml

of two large station datasets, the Global Historical Climate Network (GHCN) and the Climate Anomaly Monitoring System (CAMS). Global precipitation data are from the $2.5^{\circ} \times 2.5^{\circ}$ gridded Precipitation Reconstruction Dataset (PREC; Chen et al. 2002), which is also based on gauge observations from GHCN and CAMS.

Unless clearly specified otherwise, anomalies are calculated as departures from a 1981-2010 monthly mean climatology or, for submonthly data, a climatology that is based on the first four harmonics of the seasonal cycle. Because of this fixed 30-yr base period, longer decadal or secular trends are likely to be incorporated into the anomalies (e.g., L'Heureux et al. 2013).

\section{EVOLUTION OF TROPICAL PACIFIC OCE-} ANIC AND ATMOSPHERIC ANOMALIES.

During the 2015/16 El Niño, all of the Niño SST indices registered values that were at least among the top three in the historical record, reinforcing its categorization as one of the strongest El Niño events on record extending at least back to 1950 . Figure 1 presents the evolution of the seasonal ( 3 month) average values of the Niño SST indices during 2015/16 relative to $1972 / 73,1982 / 83$, and 1997/98. Overlapping seasonal index values are presented because ENSO is a climate phenomenon, typically identified on seasonal-to-interannual time scales. With the exception of Niño- $1+2$, the Niño indices were nearly $+0.5^{\circ} \mathrm{C}$ above average at the beginning of 2015 . This was warmer than at the start of 1997 and 1982 and likely the remnants of a borderline El Niño-neutral situation in 2014 (McPhaden 2015). Positive SST anomalies were largest near the international date line through March 2015 (Fig. 2, left). Beneath the surface, temperature anomalies were also warm in the western and central equatorial Pacific (Fig. 3, left). As in 1997, a series of westerly wind bursts during the first quarter of 2015 (Fig. 4, left) resulted in the eastward progression of a downwelling oceanic Kelvin wave (Fig. 3, left). As the thermocline deepened in the eastern Pacific, positive SST anomalies significantly strengthened near South America where the Niño-1+2 and Niño-3 indices reached $+1.5^{\circ} \mathrm{C}$ by May-July (MJJ) 2015 (Fig. 1, bottom row).

The region of the largest positive SST anomalies expanded westward from May through November 2015, which was also similar to the evolution during 1997 (Fig. 2). Primarily because of the increase of the thermocline depth and surface temperatures anomalies, NOAA, BoM, and ENFEN all declared the onset of El Niño conditions by mid-May 2015. Most Niño regions closely tracked the evolution of the $1997 / 98$ El Niño through July 2015, which, alongside model forecasts, was factored into the outlooks as corroborating information that this event would likely peak as a strong event based on warming in the Niño-3.4 and the Niño-1+2 indices. In accordance with this outlook, the Niño-3.4 and Niño-3 indices grew monotonically during the rest of 2015 , peaking near $+2.5^{\circ} \mathrm{C}$ during November-January (NDJ) 


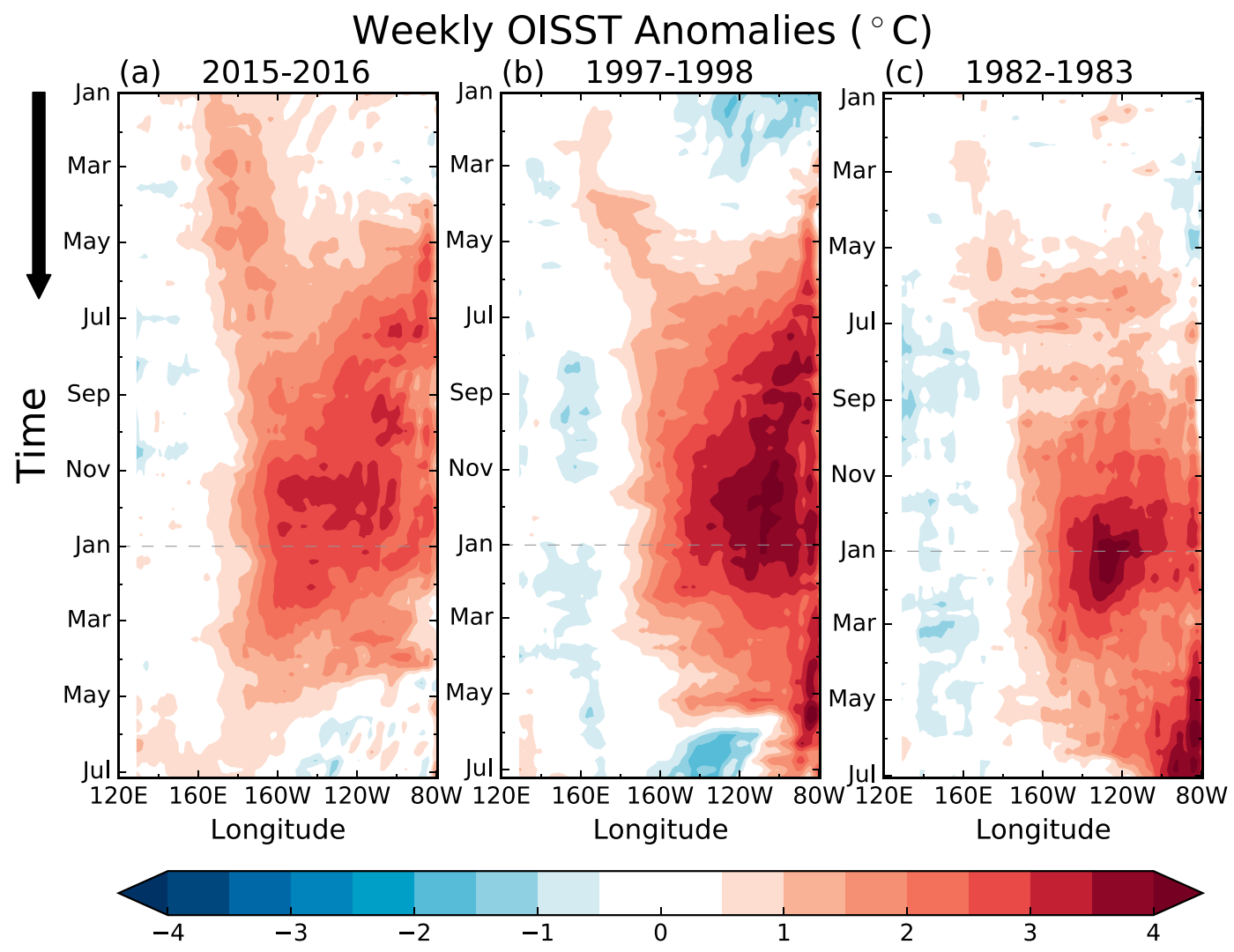

FIG. 2. Longitude-time (Hovmöller) diagram of weekly SST anomalies across the equatorial Pacific Ocean (5 ${ }^{\circ} \mathrm{S}-$ $5^{\circ} \mathrm{N}$ ) from $120^{\circ} \mathrm{E}$ to $80^{\circ} \mathrm{W}$ during (a) 2015/16, (b) $1997 / 98$, and (c) $1982 / 83$. Departures are formed by removing the first four harmonics of interpolated from daily data during 198I-2010. Data are based on weekly OISSTv2.

2015/16 (Fig. 1). However, across the eastern Pacific, the thermocline depth anomalies during NDJ 2015/16 were not as deep as 1997/98.

Going back to at least 1950, seasonal Niño-3.4 index values were near record at the peak of the event, but the spread among different datasets (Fig. 1) and the uncertainty as documented in ERSSTv4 by Huang et al. (2016) precludes clear designation as a record. The westernmost Niño-4 index values were particularly remarkable compared to the previous events, with seasonal values near $+1.0^{\circ} \mathrm{C}$ through most of 2015, and a peak just shy of $1.5^{\circ} \mathrm{C}$ during NDJ 2015/16. In contrast, the other significant El Niño events failed to reach $+1^{\circ} \mathrm{C}$. Interestingly, the 2015/16 warming in the Niño-4 region was comparable to that of the 2009/10 El Niño, which was not a major event, but had record warming in this region (Lee and McPhaden 2010).

After the midpoint of 2015, the growth in the Niño-1+2 and Niño-3 SST indices noticeably slowed relative to the 1997/98 El Niño (Fig. 1). In fact, the easternmost Niño-1+2 index did not perceptibly strengthen beyond the MJJ 2015 value of $+2^{\circ} \mathrm{C}$, which clearly fell short of the nearly $+4^{\circ} \mathrm{C}$ maximum achieved during the $1997 / 98$ and $1982 / 83$ events. While there were roughly the same number of downwelling Kelvin waves as in 1997/98, they did not have as much of an influence on the amplitude of the subsurface temperature anomalies in the eastern Pacific (Fig. 3), consistent with the smaller eastward extent, and weaker magnitude, of the westerly wind anomalies (Fig. 4). This may be tied to cooling related to the decadal shift toward stronger trade winds (e.g., $\mathrm{Hu}$ et al. 2013) or possibly related to the nonlinear convective feedback across the eastern Pacific Ocean (e.g., Takahashi and Dewitte 2016).

Indices that measure the atmospheric component of ENSO over the tropical Pacific (e.g., pressure and convection) were also indicative of an impressive El Niño in 2015/16, albeit not a record-setting one. Figure 5 (top) shows that the traditional SOI, based on the difference in sea level pressure between Tahiti minus Darwin stations (dashed lines), and the equatorial SOI (solid lines) were both substantially negative, reflecting the weakening of the Pacific Walker circulation that is typical of El Niño. During 2015/16, the SOI minimum was nearly 2 standard deviations below the 1981-2010 mean, and the minimum EQSOI value 


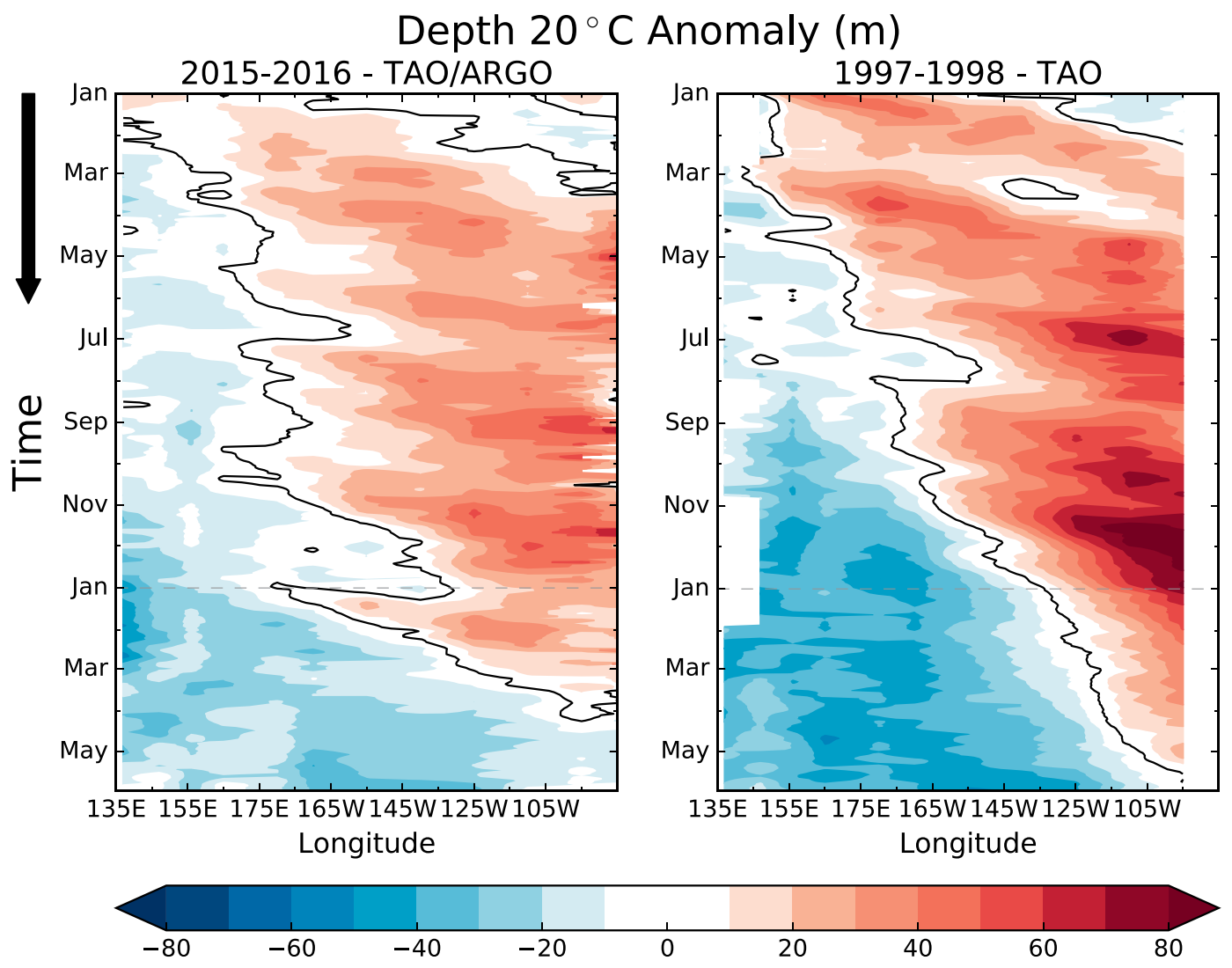

Fıg. 3. Longitude-time (Hovmöller) diagram of 5-day running averages of the $20^{\circ} \mathrm{C}$ isotherm depth (m) across the equatorial Pacific $\left(2^{\circ} \mathrm{S}-2^{\circ} \mathrm{N}\right)$ from $135^{\circ} \mathrm{E}$ to $75^{\circ} \mathrm{W}$ during (left) $2015 / 16$ and (right) 1997/98. Data are based on the TAO moored buoys from II transects and Argo floats near $85^{\circ} \mathrm{W}$. A 5 -day running mean was applied and spatial interpolation is based on Python contourf. The data were processed by the Instituto Geofisico del Peru using the 198I-2010 climatology obtained from NCEP Global Ocean Data Assimilation System (GODAS).

was approximately -2.5 standard deviations using the mean of the reanalyses, with noticeable spread among the individual datasets. The 2015/16 values were not as low as in 1982/83 (the historical record for both the SOI and EQSOI) and also fell short of 1997/98 values.

The OLR indices over the eastern and central tropical Pacific Ocean were also quite negative, indicating increased convection and rainfall over the areas of above-average SST (Fig. 5, middle and bottom panels; Chiodi and Harrison 2013; L'Heureux et al. 2015). The eastern Pacific OLR index is strongly skewed compared to the central Pacific index, reflecting nonlinearity in SSTs (e.g., Takahashi and Dewitte 2016), so the differences in evolution with $1997 / 98$ and 1982/83 are more dramatic. However, seasonal values in both indices were among the top three most significant events.

As is typical with the evolution of ENSO events, all ENSO indices weakened after the Northern Hemisphere winter of 2015/16. As the event decayed, there was a steeper dropoff in the eastern regions of Niño-1+2 and Niño-3 compared to 1982/83 and in
Niño-1+2 compared to 1997/98 (Fig. 1). The Niño-1+2 region was most similar to the trajectory of 1972/73, which was in stark contrast to the 1982/83 event that maximized during May-July of the second year and the 1997/98 event. During the latter two events, the anomalous westerly winds across the eastern Pacific helped to maintain larger positive SST anomalies (Vecchi and Harrison 2006), which were absent in 2015/16 (Fig. 4). After April-June (AMJ) 2016, the Niño regions returned to values reflective of ENSOneutral conditions, though the decrease in Niño-4 lagged the other El Niño events because it achieved higher SST anomalies at its peak.

Overall, one of the more distinct aspects of the 2015/16 El Niño, compared to 1997/98 and 1982/83, was the cooler SST anomalies in the east and warmer SST anomalies in the west; this was especially noticeable at the maximum in November and December 2015 (Fig. 2). Consistent with the Bjerknes feedback (coupling between SST and wind anomalies), Fig. 4 shows that the westerly wind anomalies from August through December 2015 were not as strong as in the 


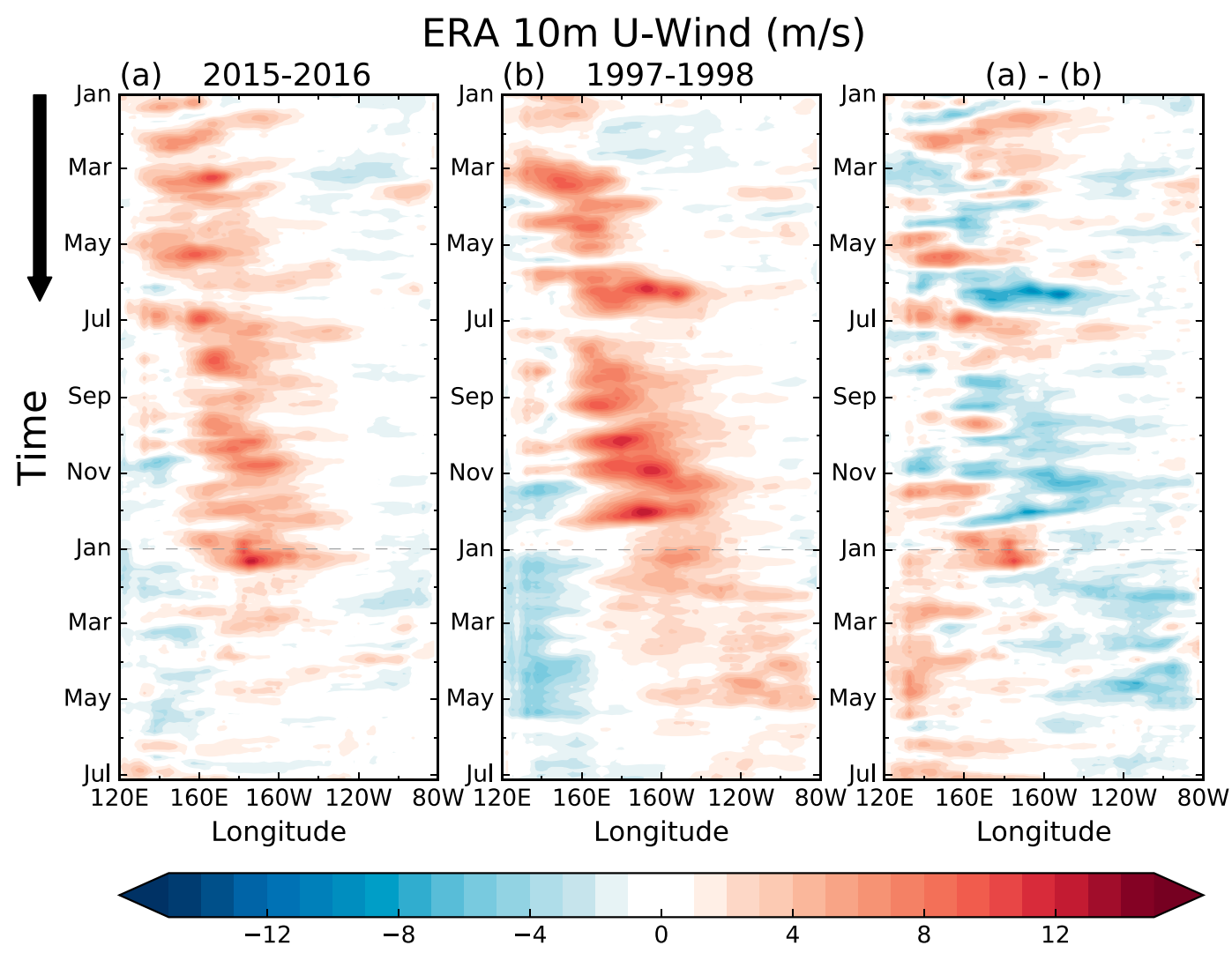

FIG. 4. Longitude-time (Hovmöller) diagram of daily $10-\mathrm{m}$ zonal wind anomalies across the equatorial Pacific Ocean $\left(5^{\circ} \mathrm{S}-5^{\circ} \mathrm{N}\right)$ from $120^{\circ} \mathrm{E}$ to $80^{\circ} \mathrm{W}$ during (a) $2015 / 16$ and (b) $1997 / 98$, and (c) the difference between $2015 / 16$ and 1997/98. Departures are formed by removing the first four harmonics of interpolated daily data during 1981-2010. Data are based on ERA-Interim.

same months in 1997 over the central and eastern equatorial Pacific Ocean [this is also replicated using NCEP Climate Forecast System Reanalysis (CFSR) 10 - $\mathrm{m}$ winds; not shown]. Hence, relative to the anomalies of the last major El Niño, the zonal or east-west differences in anomalous SST, subsurface temperatures, winds, and pressure during the last half of 2015 were not as pronounced across the equatorial Pacific Ocean.

Figures ES1 and ES2 in the online supplement to this article (http://journals.ametsoc.org/doi/l0.II75 /BAMS-D-16-0009.2) also indicate that the anomalous meridional SST gradient was more relaxed during $2015 / 16$ relative to $1997 / 98$ and $1982 / 83$. Typically, during El Niño, SSTs are above average on the equator and then taper to smaller values off the equator. During $2015 / 16$, across the eastern Pacific $\left(150^{\circ}-90^{\circ} \mathrm{W}\right)$, the anomalous SSTs were relatively warmer just to the north of the equator $\left(5^{\circ}-10^{\circ} \mathrm{N}\right)$ and cooler immediately along the equator $\left(2.5^{\circ} \mathrm{S}-2 \cdot 5^{\circ} \mathrm{N}\right)$. Figure ES2 suggests that the weakening of the typical anomalous El Niño meridional gradient was associated with a corresponding dearth of enhanced convection across the central and eastern Pacific Ocean (also see Fig. 5).
The exceptional Niño-4 SST index values reflect the enhanced westward extension of positive SST anomalies during 2015/16. While one could define this pattern as a major El Niño event with a bit of a "central Pacific" flavor in a relative sense compared to the other major events, we would be remiss not to point out the broad stretch of above-average SSTs extending across the central and eastern equatorial Pacific. In fact, the SST anomalies with the largest amplitudes occurred within the east-central Pacific and, in particular, within the Niño-3.4 region (Fig. 1). Figure 6 shows that the observed SST anomalies spatially correlate very well onto the pattern that results from regressing SST anomalies onto the Niño-3.4 index. At its peak in November-January, the pattern of SST anomalies extended farther westward and projected better onto the Niño-3.4 index than in previous major El Niño events (Fig. ES1).

In addition to the most recent El Niño projecting well onto the Niño-3.4 index relative to past years between 1982 and 2016 (cf. individual black dots in the bottom panels of Fig. 6), the 2015/16 boreal winter also was associated with nearly equal weights 
- Fig. 5. Evolution of (top) seasonal (3 month) averaged values of the traditional Tahiti-Darwin station-based SOI (dashed lines) and EQSOI (solid lines), (middle) central Pacific OLR index, and (bottom) eastern Pacific OLR index during 2015/16 (red), $1997 / 98$ (blue), and $1982 / 83$ (green). The EQSOI is based on the difference between the $5^{\circ} \mathrm{N}-5^{\circ} \mathrm{S}, 80^{\circ}-130^{\circ} \mathrm{W}$ and $5^{\circ} \mathrm{N}-5^{\circ} \mathrm{S}, 90^{\circ}-$ $140^{\circ} \mathrm{E}$ regions. CP OLR is based on the $5^{\circ} \mathrm{S}-5^{\circ} \mathrm{N}, 170^{\circ} \mathrm{E}-$ $140^{\circ} \mathrm{W}$ region and the EP OLR region covers $5^{\circ} \mathrm{S}-5^{\circ} \mathrm{N}$, $160^{\circ}-110^{\circ} \mathrm{W}$. Thin solid lines in the top panel correspond to the NCEP CFSR (Saha et al. 2010), NCEP-NCAR reanalysis (Kalnay et al. 1996), NCEP-Department of Energy (DOE) Atmospheric Model Intercomparison Project (AMIP) II reanalysis (Kanamitsu et al. 2002), ERA-Interim (Dee et al. 20II), Japanese 55-year Reanalysis (JRA-55) (Kobayashi et al. 2015), and NASA Modern-Era Retrospective Analysis for Research and Applications (MERRAI) and MERRA2 (Rienecker et al. 20II). Thin solid lines in (middle) and (bottom) are from AVHRR and the HIRS v2r2 and v2r7. The thick solid line in all panels is the average of individual datasets. All indices are standardized using monthly means and standard deviations during $1981-2010$.

( $\sim 2$ standard deviation values) in the so-called $\mathrm{E}$ and C indices of Takahashi et al. (2011). While there are many different indices available for evaluating ENSO flavors, the E and C indices isolate SST anomalies in the eastern and central equatorial Pacific Ocean, respectively. For example, the 1982/83 and 1997/98 El Niño had strongly projected onto the $\mathrm{E}$ index relative to $2015 / 16$, while the previous El Niño in 2009/10 was well captured by the $C$ index. Therefore, the most recent event was approximately in the middle of the ENSO continuum (Capotondi et al. 2015), with less intensification in the far eastern Pacific Ocean.

\section{MODEL FORECASTS OF THE NIÑO-3.4} SEA SURFACE TEMPERATURE INDEX.

Operational forecast centers consider their own inhouse climate models and a number of model plumes, which display members and/or ensemble means from an assortment of different models. The IRI/ CPC multimodel plume of Niño-3.4 SST forecasts is perhaps the longest-running, operational collection of various models, which includes both dynamical and statistical models. Once a month, agencies around the world provide ensemble-average, overlapping seasonal Niño-3.4 SST index values going out to 9 months. The exact dates of initialization, number of members in the ensemble mean, and mean bias correction is left up to the model providers.

An average of the multimodel ensemble (MME) of just over 15 "dynamical" and nearly 10 "statistical" models is displayed in the latest updates of the IRI/
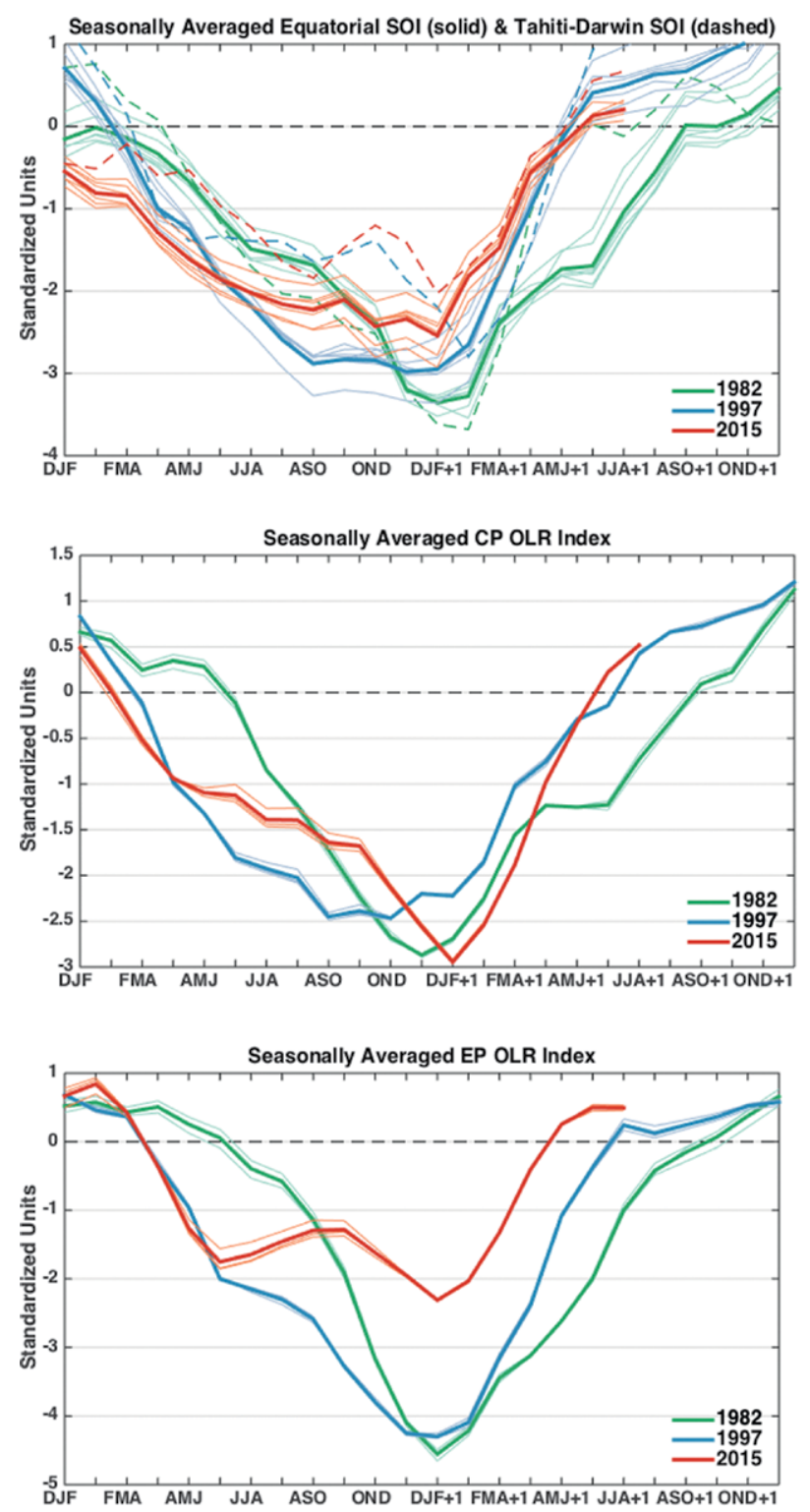

CPC plume. ${ }^{1}$ However, embedded within the dynamical category are a set of about five models called intermediate-complexity coupled models (ICMs) that are not comprehensive like the state-of-the-art dynamical models and rely more heavily on statistical methods. Over the last couple of years, in general, the skill scores associated with the dynamical average improve when the ICM results are excluded, and the ICM-only average is not an improvement upon the

\footnotetext{
${ }^{1}$ Dynamical models typically require supercomputing resources, involve data assimilation systems, and explicitly calculate the future state based on the physics of the atmosphere, land, ice, and oceans, and their interactions. Statistical models can be run on a desktop computer and rely upon historical relationships in the observational record and assume these relationships will hold into the future.
} 


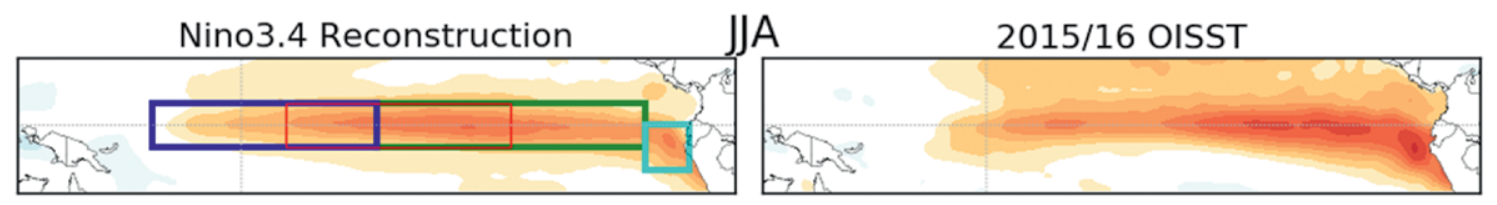

NDJ
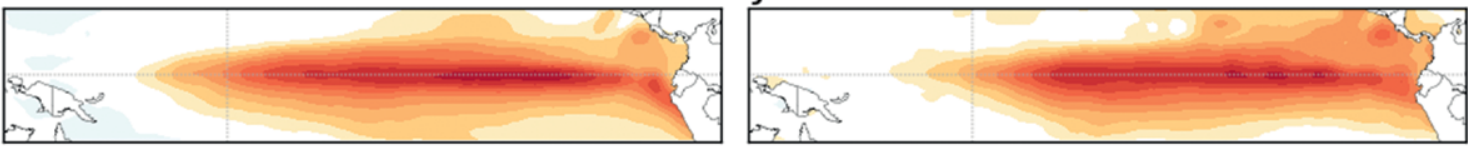

FMA
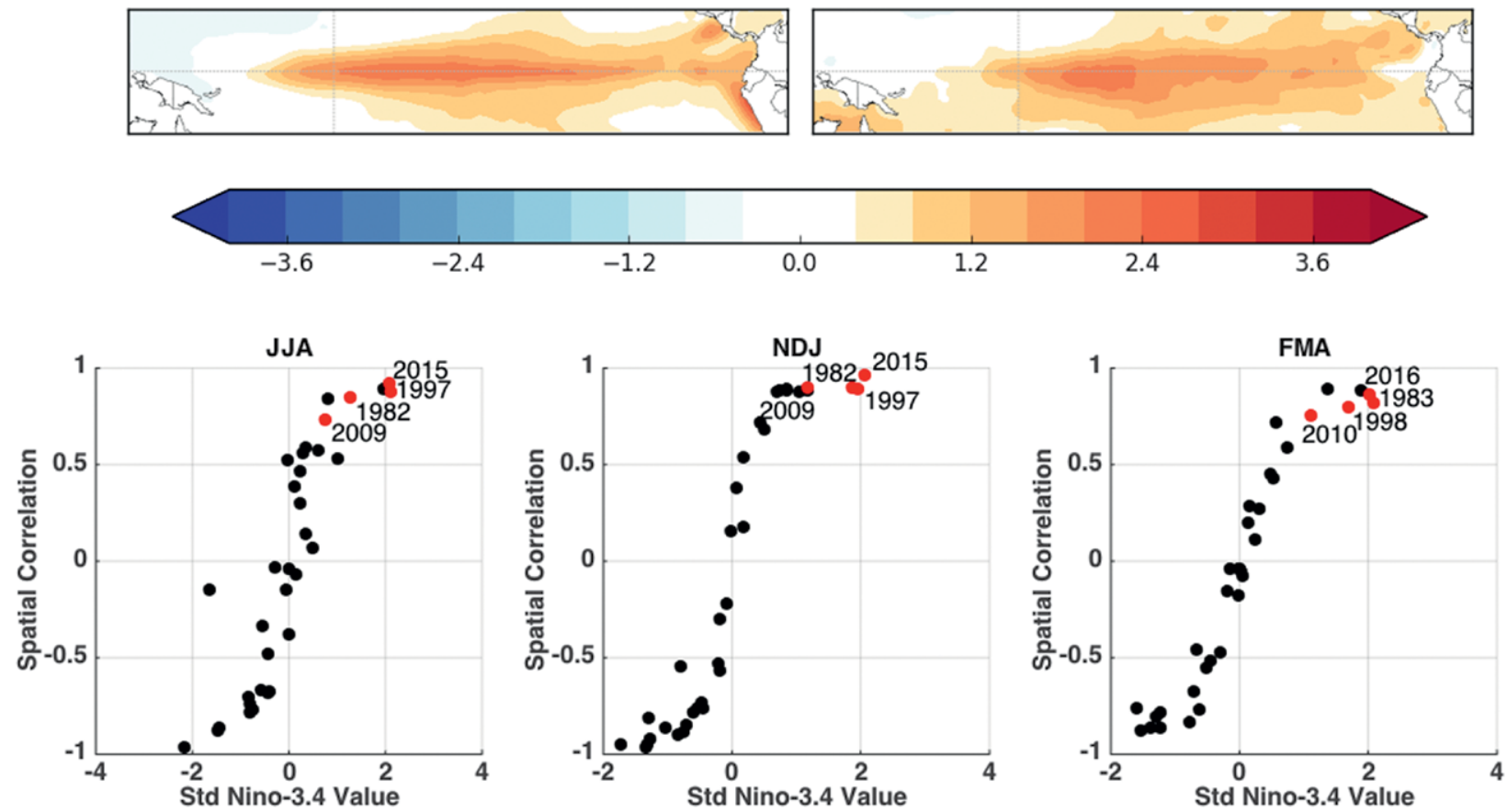

FIG. 6. SST anomaly reconstruction based on the weighted regression map of (top left) the Niño-3.4 index and (top right) the observed SST anomalies during 2015/16 for seasonal averages during JJA, NDJ, and FMA. (bottom) The spatial correlation between the reconstruction and observations is shown along the ordinate and the seasonal average Niño-3.4 index value is shown along the abscissa. Each dot represents a single year between 1982 and 2016. The red dots indicate the 2015/16 El Niño, two other strong El Niños in 1997/98 and 1982/83, and the 2009/10 EI Niño, which is the EI Niño prior to the 2015/16 event. The top-left panel displays the Niño-4 region (blue), Niño-3.4 region (thin red), Niño-3 region (green), and Niño-I+2 region (aqua). Departures are formed by removing monthly means during 198I-20I0. Data are based on weekly OISSTv2.

statistical model average (see Figs. ES3-ES5 in the online supplement to this paper).

Figure 7 illustrates, in grayscale, every individual model forecast made for targets during DecemberFebruary (DJF) 2013/14 through February-April (FMA) 2015/16 for the dynamical (top panel), which include the ICMs, and statistical models (bottom panel). The solid blue and red lines lie within the spread of the gray lines because they represent the MME average of the individual models. Generally, the MME mean tends to be more skillful than any individual model because the averaging helps to cancel out model errors (Palmer et al. 2004; Kirtman et al. 2014). However, a single observation will be a result of some predictable signal (e.g., ENSO dynamics) and unpredictable, random noise, while averaging in the MME is designed to suppress the unpredictable noise in order to enhance the signal. ENSO events are forecast opportunities when the role of the predictable signal becomes greater than the typical level of noise 
(e.g., Vecchi et al. 2006; Kumar and Hu 2014).

The $2015 / 16$ predictions of the Niño-3.4 SST index were successful, especially when juxtaposed with the low ENSO predictability of the previous decade (Barnston et al. 2012) and the predictions of an El Niño in 2014/15 that did not grow as expected (McPhaden 2015). For target periods during 2014, the statistical MME average anomalies (blue lines) were closer to the observed anomalies (black line), while the dynamical MME average (red lines) largely overforecasted the amount of warming in Niño-3.4. But, after mid-2014, the forecasts improved and were generally closer to the modest warming (Niño-3.4 near $+0.5^{\circ} \mathrm{C}$ ) observed for several seasons in 2014/15.

Coming out of the 2014/15 Northern Hemisphere winter, a number of dynamical and statistical models were predicting a decrease in the Niño-3.4 index. Once the observational data showed warming in early 2015, many dynamical and statistical models began to forecast a more significant El Niño. However, both MME averages underestimated the peak strength of the episode, not catching onto the possibility of $\mathrm{a}+2^{\circ} \mathrm{C}$-sized event until mid-July 2015 for the dynamical and mid-August 2015 for the statistical models.

By August 2015, official ENSO outlooks were more assertively playing up the potential of a historically strong event. At this time, public communications explicitly favored an event rivaling the peak amplitudes of past major El Niños. As far back as May 2015, BoM noted that the dynamical model averages from the World Meteorological Organization (WMO) Global Producing Center of Long Range Forecasts (a subset
IRI/CPC Dynamical Models (All Leads)

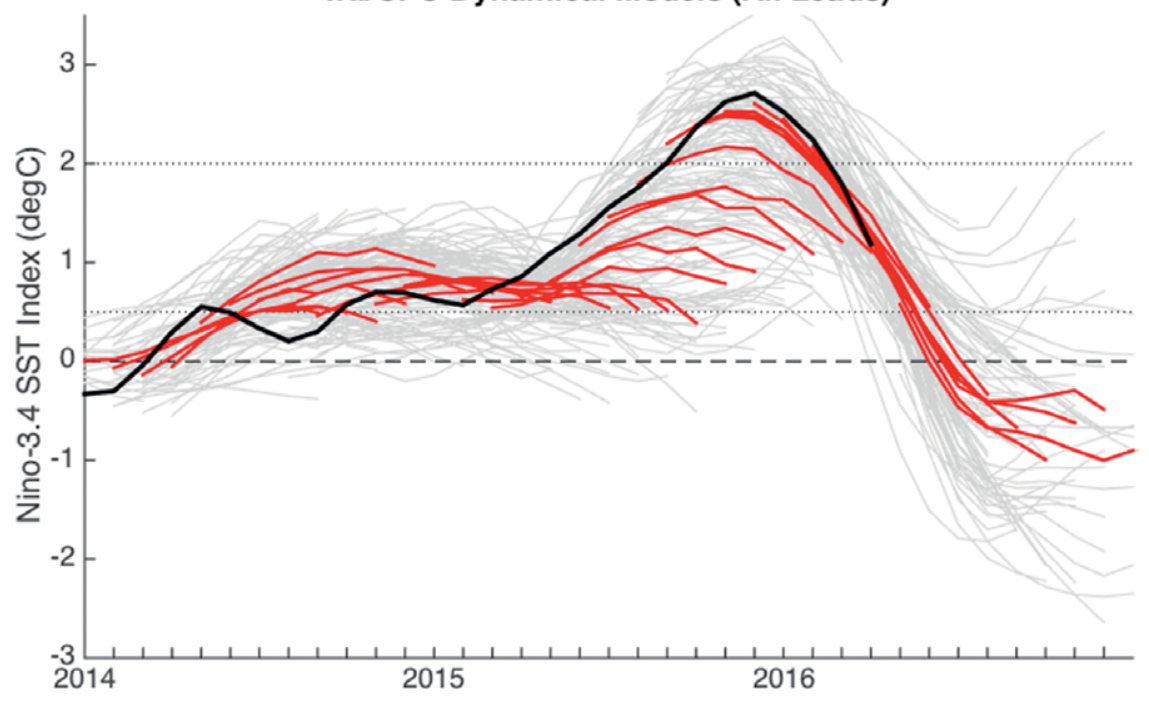

IRI/CPC Statistical Models (All Leads)

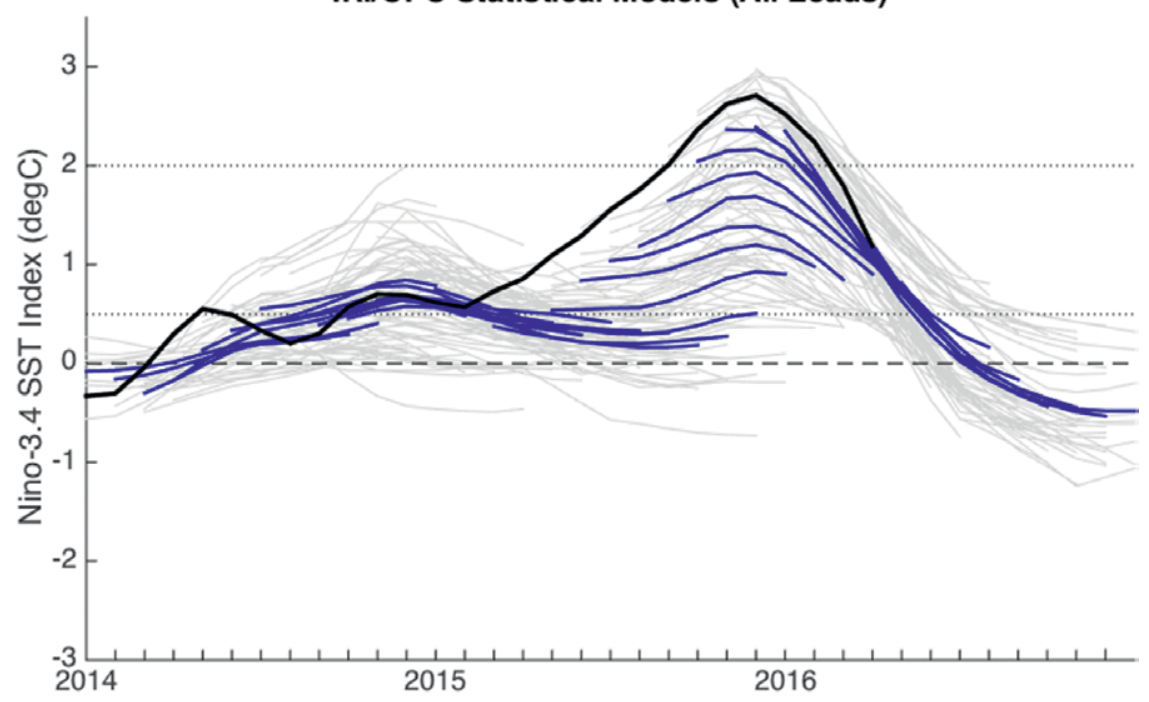

FıG. 7. Predictions of the Niño-3.4 index for overlapping, seasonal target periods from DJF 2013/14 to FMA 2016 for the (top) dynamical and (bottom) statistical models drawn from the IRI/CPC plume. Gray lines show every individual model forecast and the red and blue lines show the dynamical and statistical multimodel averages, respectively. The thick black line shows the observational databased on seasonal averages of daily OISST data.

of models in the IRI/CPC plume) were in excess of $+2^{\circ} \mathrm{C}$ for the upcoming fall/winter seasons. ENFEN also noted that Niño-1+2 forecasts created using the North American Multimodel Ensemble (Kirtman et al. 2014) approached the strength predicted for $1997 / 98$.

Statistical models largely lagged the growth rate seen in the dynamical models in 2015 and never foresaw the peak amplitude of the event as well as the dynamical models. This disparity is consistent with past ENSO forecasts; in general, the statistical models often lag the dynamical models because they are 

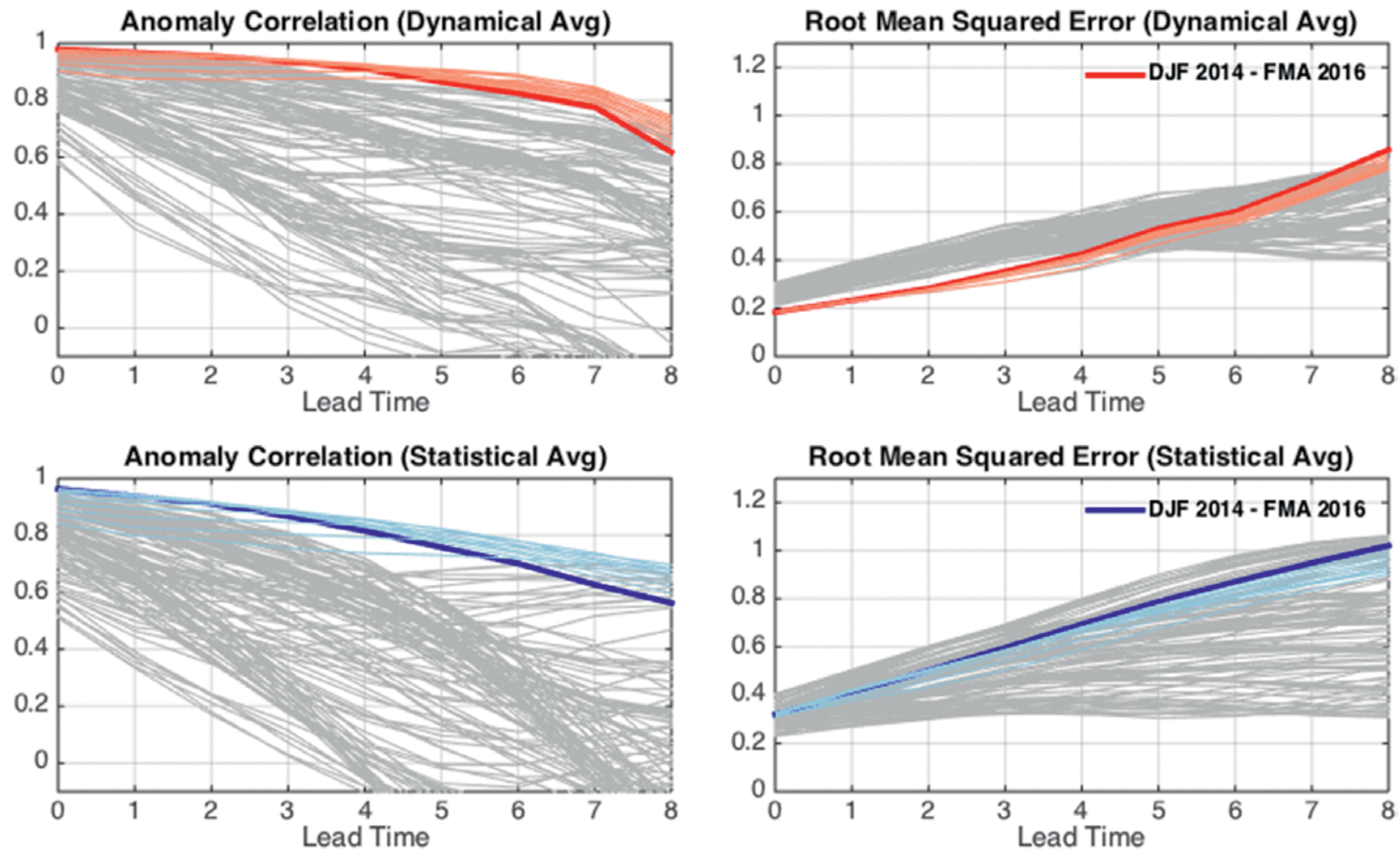

FIG. 8. The (left) ACs and (right) RMSEs between the observations and multimodel averages of the (top) dynamical and (bottom) statistical forecasts of the Niño-3.4 index. The thick blue and red lines show the skill for targets from DJF 2013/14 to FMA 2016. The gray lines are the skill of past windows of 26 consecutive overlapping seasons, each sliding by one season, with thin blue and red lines showing windows that overlap with the DJF 2013/I4-FMA 2016 period. Forecast data are verified against seasonal averages of daily OISST data.

not configured to take advantage of the most recent changes in the observational evolution (e.g., Barnston et al. 2012). Many statistical models are trained on monthly or seasonal averages, so they cannot resolve the short-term changes (e.g., westerly wind bursts) that the dynamical models are initialized with. Thus, the statistical model "success" during 2014 may be due to the fact they were not equipped to react to conditions that the dynamical models saw as important precursors or amplifiers of El Niño growth.

Evaluating skill using the temporal anomaly correlation (AC) within a $\sim 2$-yr sliding interval, the dynamical and statistical MME average forecasts were the highest for the most recent event since the IRI/CPC model plume was created in 2002 (see the appendix for details on the forecast verification metrics). Figure 8 (left column) shows that targets during DJF 2014-FMA 2016 (thick red and blue lines) had the largest AC results compared to equivalent length time ranges going back to 2002 (gray lines are past windows of 26 consecutive overlapping seasons, each sliding by one season). The thinner red and blue lines correspond to ranges that are strongly associated with the recent period [e.g., from NDJ 2013 to
January-March (JFM) 2016]. The ACs were in excess of 0.6 going out to lead- 8 for both model types, with dynamical models demonstrating slightly more skill for lead- 0 to lead-7. The dynamical MME average had an AC greater than 0.9 going out to lead-4, while the statistical MME average only did so going out to lead-2. The AC metric rewards a good fit between the forecast and observational time series during a larger event (relative to a good fit during a smaller event) and, so, the greater AC results were partially due to the fact that this event was, by far, the largest in the model record (2002-16) and was well forecasted.

Compared to the $\mathrm{AC}$, the root-mean-square error (RMSE) was generally not as skillful relative to past IRI/CPC model forecasts of the Niño-3.4 index (Fig. 8, right column). For the statistical MME, the RMSEs were roughly $0.8^{\circ}-1.0^{\circ} \mathrm{C}$ past lead -4 , while they were $0.5^{\circ}-0.8^{\circ} \mathrm{C}$ for the dynamical MME. For the longest leads, the statistical and dynamical models had among the largest errors going back to 2002. Conversely, for the shorter lead times (lead-0 to lead-4), the dynamical MME average had among the smallest errors in the IRI/CPC plume history. Beyond lead-1, the statistical model RMSE remained roughly in the 
- Fig. 9. Scatterplots of observed Niño-3.4 index values (plotted along the abscissa) against (top) lead0 , (middle) lead-4, and (bottom) lead-8 forecasts based on the (left) dynamical and (right) statistical multimodel averages (plotted along the ordinate) for all seasonal ( 3 month) averages dating back to the beginning of the model plume in Feb 2002. The color shading shows the year of the target season, and the numeral highlights the location of the NDJ target season and year (displaying last two digits between 2002 and 2015). The $r$ value in the top-left corner is the correlation between the observations and forecasts made between February 2002 and April 2016. Forecast data are verified against seasonal averages of daily OISST data.

upper quartile of the historical error spread, while improving to the midpoint of the spread for the very shortest leads. Figure 9 indicates that all multimodel averages tend to underestimate the observed values the stronger the event becomes and the longer the lead time (for both El Niño and La Niña). This result may be unsurprising for a large-amplitude event, but the low errors $\left(0.2^{\circ}-0.3^{\circ} \mathrm{C}\right)$ in the dynamical models at short lead times were rather exceptional.

There are other multimodel plumes, such as the North American Multimodel Ensemble (Kirtman et al. 2014) and the European Multimodel Seasonalto-Interannual Prediction project (EUROSIP; Palmer et al. 2004), that are increasingly relied upon by forecasters who regularly comment on the probability of ENSO events. The advantage of these plumes is that they additionally display the individual ensemble members, which capture the intrinsic "noise" or uncertainty associated with climate forecasts. Probabilistic verification metrics also need
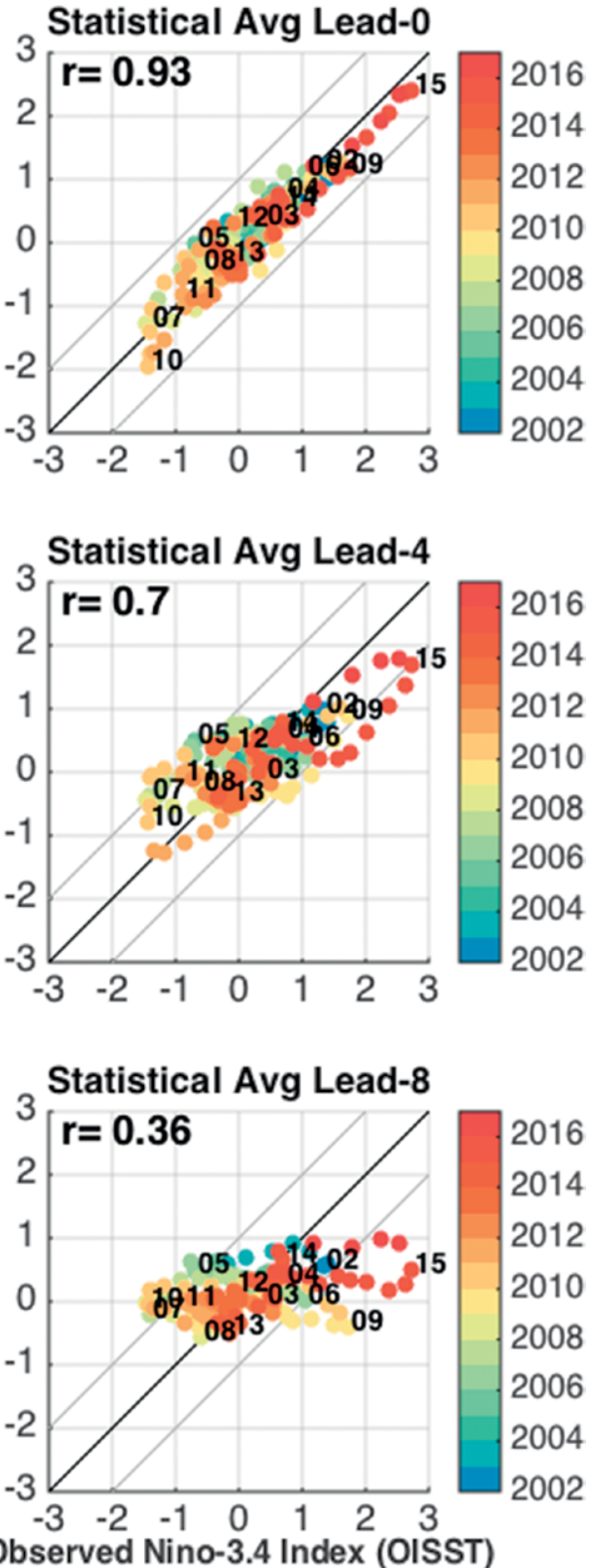

to be applied to evaluate whether observations were within the spread of outcomes. It is also worth testing whether the spread of model forecasts reflects the real-world uncertainty because it is generally thought most models are underdispersive or tend to be overly confident (e.g., Shi et al. 2015).

Not only is there uncertainty associated with the models, but there is uncertainty among the observational data used as verification (e.g., Goddard et al. 2009). In general, the prevailing trend is toward the development of higher-resolution products, so daily OISST was selected herein as the basis for model verification. But, undoubtedly, statistical models, with their generally coarser inputs and outputs, are at an inherent disadvantage when compared against a high-resolution 

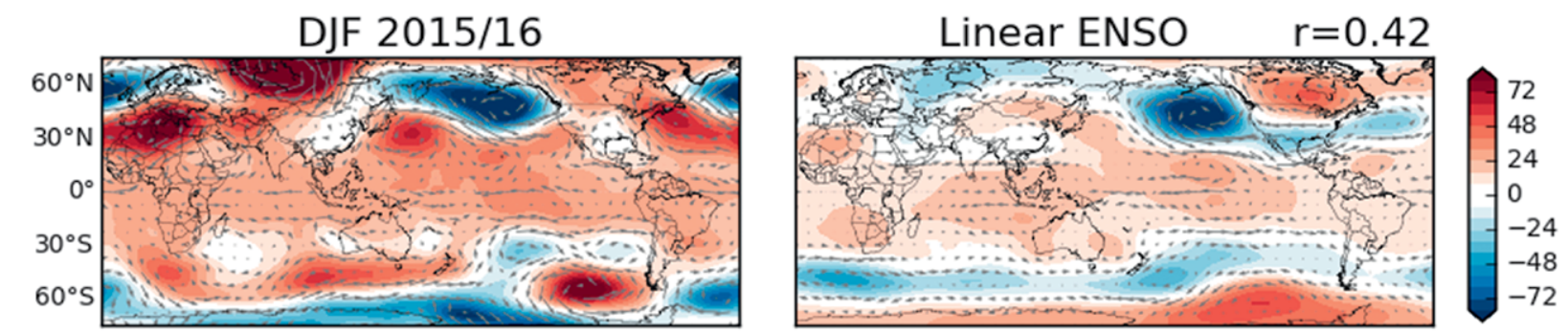

$10 \mathrm{~m} / \mathrm{s} \longrightarrow$
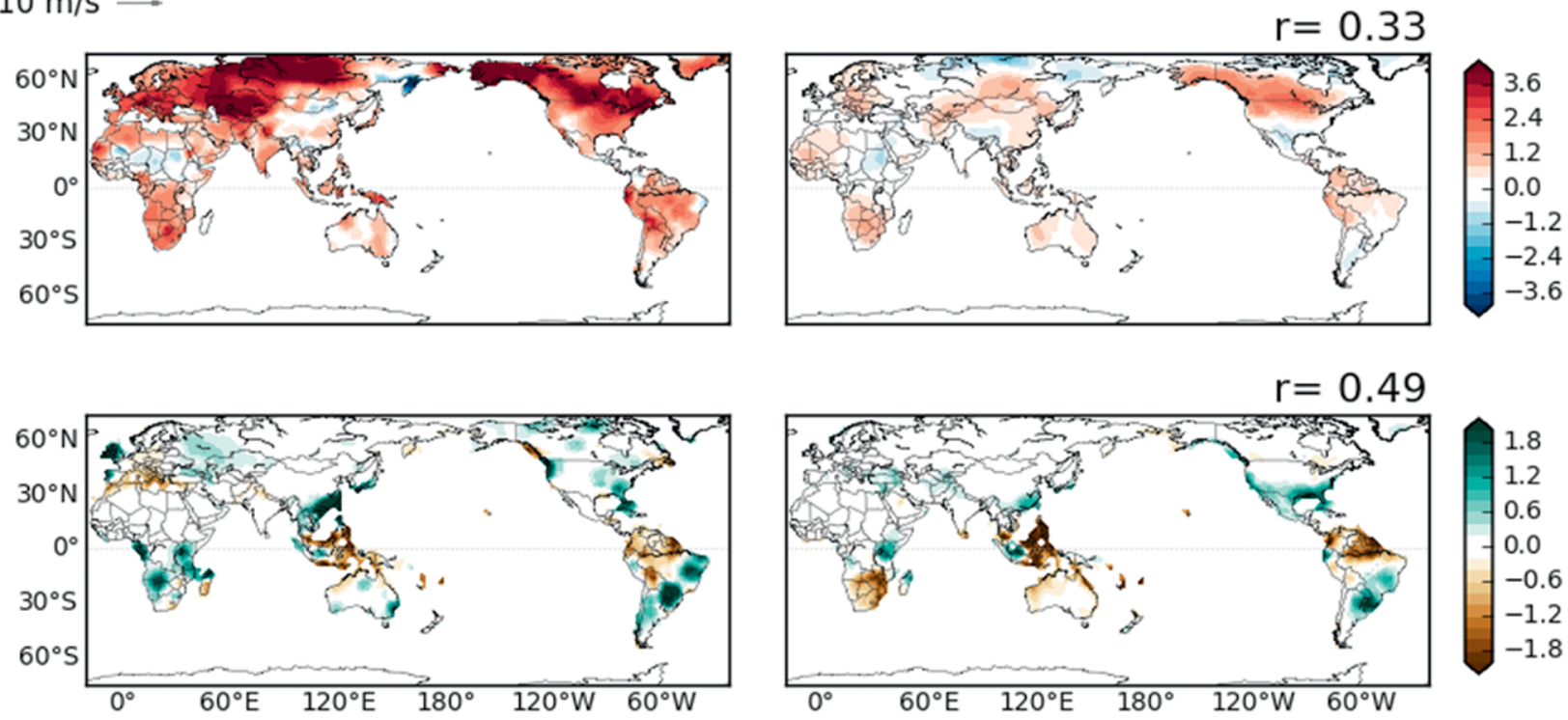

Fig. 10. DJF 2015/16 anomalies of (top) 500-hPa geopotential height and winds, (middle) surface temperature, and (bottom) precipitation. (left) The observational data, and (right) the reconstruction for $2015 / 16$ (weighted regression map of the Niño-3.4 index). The $r$ values show the spatial correlation coefficient between the observational and the reconstructed anomalies (cosine weighted by latitude). Geopotential height and wind data are from the NCEP-NCAR reanalysis, the temperature is from the gridded GHCN+CAMS dataset, and precipitation data are from the gridded PREC dataset. Departures are formed by removing monthly means during 198I-2010.

observational dataset. Because statistical models are often built and trained with data from statistical reconstructions (because of the longer records they provide), it may be worthwhile to develop new strategies to increase the resolution of these datasets.

\section{GLOBAL ANOMALIES DURING DECEM-}

BER-FEBRUARY. The strength of El Niño is usually greatest during the Northern Hemisphere winter and its impacts generally widespread, with pronounced changes in the Walker circulation across the global tropics and anomalous wave trains that extend into the extratropical latitudes of both hemispheres (Bjerknes 1969; Horel and Wallace 1981). At mid- to high latitudes, changes to the long-wave pattern interact with synoptic-scale eddies, resulting in the persistence and recurrence of storms and other synoptic events over certain regions. As a result, the influence of El Niño is often identified in seasonal averages and not in shorter time averages.
During DJF 2015/16, above-average 500-hPa geopotential heights dominated the tropical latitudes and the midlatitudes of both hemispheres, with a large anticyclonic anomaly over Siberia during DJF 2015/16 (Fig. 10, top row). Associated with this pattern, strongly above-average temperatures prevailed over most of the globe, with particularly significant positive anomalies over the mid- to high latitudes of the Northern Hemisphere (Fig. 10, middle row). The most significant regions of increased precipitation were located over the northwestern and southeastern United States, southern and eastern South America, southeast China, and just south of the equator in eastern Africa (Fig. 10, bottom row). Drier conditions were prominent over northern South America and around Indonesia. So, how well did this observed pattern relate to El Niño?

One way to quantify the match is to compute the spatial correlation coefficient between the observed pattern and a typical El Niño pattern. To estimate the 
latter, detrended DJF climate anomalies are regressed onto standardized and detrended values of the DJF Niño-3.4 index from 1979 to 2014. The regression map is then weighted with the observed DJF 2015/16 Niño3.4 index value in order to obtain the same units as the observational data (Fig. 10, right column). Thus, the analysis shown here is assuming a linear response to Niño-3.4 SST anomalies and will exclude nonlinear relationships. For all three variables in Fig. 10, the spatial correlation coefficients between the observations and the linear ENSO pattern are between 0.3 and 0.5 , which means roughly $10 \%-25 \%$ of the spatial variance was explained by ENSO during DJF 2015/16. While significant, this is not very large, and indicates that there were other sources of variability during the Northern Hemisphere winter that were not well described by this linear estimate of El Niño.

The aspects of the circulation that were perhaps most consistent with El Niño were the distinctive wave trains tracing a great-circle route across the North and South Pacific Oceans. Anomalous cyclonic flow was observed in the Gulf of Alaska and middle latitudes of the South Pacific Ocean, with anomalous anticyclones poleward and east of the anomalous troughs over Canada and closer to West Antarctica. However, the cyclonic anomaly in the Gulf of Alaska and the anticyclonic anomaly near West Antarctica were shifted northward compared to the typical El Niño response. Over North America, the anomalous warmth projected well onto the El Niño pattern, but the observed anomalies were more intense and widespread than otherwise expected with El Niño. The anticipated pattern of below-average temperatures and heights over the southern tier of the United States did not emerge. Globally, many of the regions that typically experience warmer conditions during El Niño were also above average in 2015/16, and these anomalies were more prominent.

Relative to the temperature anomalies, precipitation was more consistent with El Niño during DJF $2015 / 16$. However, there were some notable exceptions from the El Niño pattern, such as the lack of increased precipitation over the southwestern and south-central United States. Likewise, southernmost Africa was not as dry as one might expect from an El Niño during DJF-though dry conditions over southern Africa were more prominent during August-October (ASO) through October-December (OND) 2015 (not shown). In northern Australia, December brought significantly more rainfall than normal, though both January and February were very much below the median-more in line with El Niño expectations. During the 1982/83 and 1997/98 events, devastating rainfall impacted Ecuador and coastal Peru during boreal winter/spring, but this was much weaker in $2015 / 16$. However, the expected drier conditions in the Andean region did prevail during the recent event [see Fig. ES6, which because of low station coverage provides a comparison with Tropical Rainfall Measuring Mission (TRMM) data].

To examine longer-term changes, the $\sim 35$-yr linear trend was computed (with its start point at the beginning of the modern satellite era). Interestingly, this simple estimate nearly rivals the ENSO anomalies as a descriptor in the $500-\mathrm{hPa}$ geopotential height anomalies, with a spatial correlation coefficient of 0.37 during DJF 2015/16 (Fig. ES7). Upon inspection, this is found to be largely due to the Southern Hemisphere trend toward lower heights over Antarctica and higher heights spanning the middle latitudes, which matches well with the observed anomalies. Neither the DJF linear trends in temperature nor precipitation anomalies correlate significantly with the observed pattern (Fig. ES7).

To estimate the portion of the observed DJF $2015 / 16$ variability that was not related to either the linear trend or linear ENSO, the summed maps are subtracted from the observations (Fig. 11). The resulting so-called residual pattern will still include nonlinearity in ENSO or any other variability that is not well described by the linear trend or linear ENSO. The stochastic nature of the atmosphere will also result in event-to-event differences. We find that the residual anomalies are highly correlated to the observed pattern with spatial correlation coefficients between 0.5 and 0.8 . The linear removal clearly does an adequate job of removing the elevated heights in the tropics and the typical anomalous wave trains that span the extratropical North and South Pacific during El Niño. What remains are zonal bands of above-average heights encircling the middle latitudes of both hemispheres, with below-average heights located poleward (the only notable exception being the large anticyclonic anomaly near Siberia). Thus, the residual identifies a nearly global, poleward shift in the midlatitude westerly wind anomalies or jet streams. Accompanying this shift in the Northern Hemisphere, the residual of precipitation is strikingly La Niña-like over the contiguous United States, with rainfall enhanced over the Pacific Northwest and suppressed along the southern tier. Western Europe is also wetter than average, likely because of anomalous westerly flow. Similarly, in the Southern Hemisphere, an anomalous increase in precipitation is evident over southeastern Australia and southern Africa, perhaps due in part to the easterly wind 


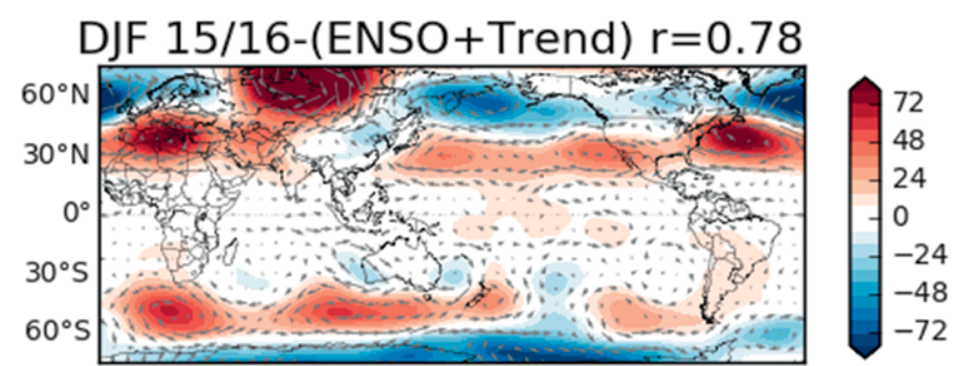

$10 \mathrm{~m} / \mathrm{s} \longrightarrow$
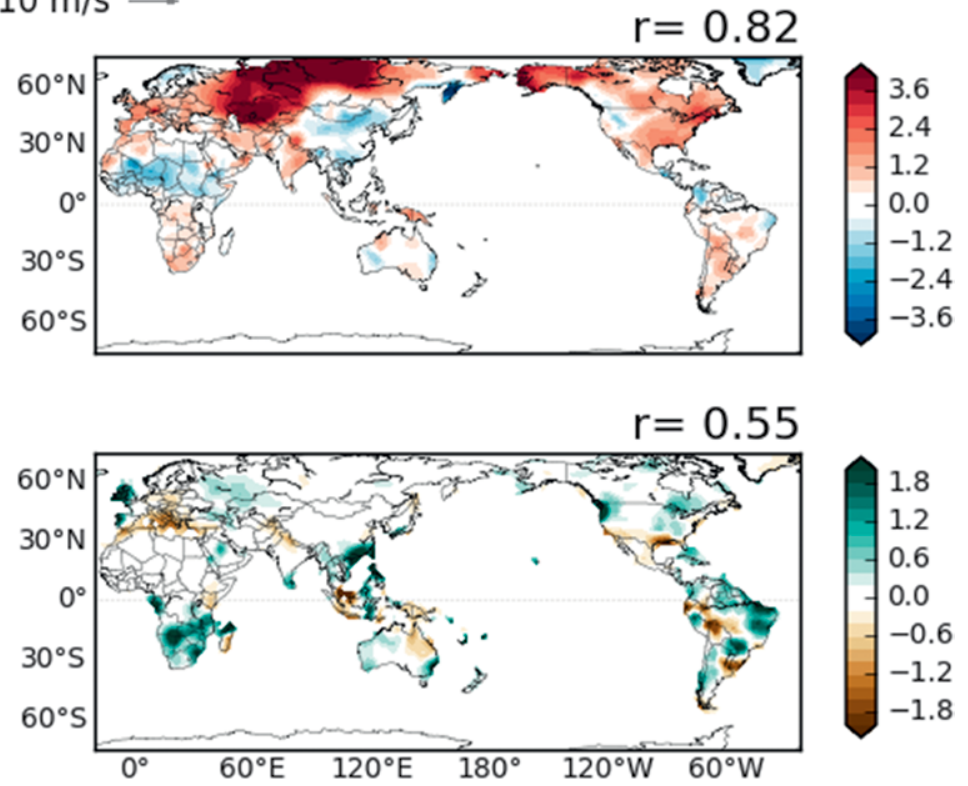

Fig. II. As in Fig. 10, but showing the residual anomalies formed from subtracting the trend plus ENSO reconstruction from the observational data. The $r$ values show the spatial correlation coefficient between the observational and the residual anomalies. et al. 2007; Murphy and Timbal 2008; Thomas et al. 2015).

Overall, it appears that El Niño coupled with a poleward shift in the jet streams significantly influenced the global climate during December-February 2015/16. It is possible that nonlinearity in El Niño (e.g., the specific location of the strongest SST anomalies) contributed to the departures from the classically linear anomalies across the globe. Also differences from the linear pattern can be expected to occur simply because of sampling variability, with event-to-event differences naturally arising because of the limited record. It is interesting that a nearly hemispheric structure in the residual circulation was uncovered, which suggests an origin that was not simply isolated to the Pacific sector. The zonal structure may have arisen from random extratropical internal atmospheric variability, aided by feedbacks between eddies and the zonal mean flow (e.g., Limpasuvan and Hartmann 2000). Also, positive temperature anomalies throughout the tropical troposphere may have contributed to the poleward shift in the jet (Butler et al. 2010; Lim et al. 2016). A final possibility for the departure from the linear ENSO estimate is the potential influence of anomalies off the ocean on the equatorward side of the anomalous ridges. The northward shift of the jet (more midlatitude ridging) and strong anomalous anticyclone near Siberia also overlaps with the strongly above-average temperatures across the Northern Hemisphere extratropics.

Despite the fact the observed and residual circulation anomalies have a distinctive annular appearance in the Northern Hemisphere, the DJF 2015/16 Arctic Oscillation (AO) index value was near zero when standardized relative to DJF seasons over 1979-2016. In the Southern Hemisphere, the DJF Antarctic Oscillation (AAO) index was more significant with a positive value of 0.8 standardized units. This outcome was somewhat surprising given El Niño is often associated with negative values of the AAO during November-February (e.g., L'Heureux and Thompson 2006). Instead, increased rainfall over portions of southeastern Australia during DJF 2015/16 appears consistent with the overall positive trend in the AAO (also reflected in Fig. ES7; Hendon subseasonal activity across the global tropics (e.g., Kelvin waves, Madden-Julian oscillation), which exerted an influence on tropical rainfall and was aliased into the seasonal averages. We leave it to others to provide a more exhaustive attribution of the possible drivers of the 2015/16 climate anomalies, including exploring other seasons, which can have a greater influence on certain countries (e.g., Australian impacts are largest during the Southern Hemisphere spring).

\section{SUMMARY AND FUTURE CONSIDER-}

ATIONS. Most atmospheric and oceanic indices suggest the 2015/16 El Niño was among the top three strongest El Niño events in the historical record dating back to 1950 . While it was not unequivocally a record, there were several ways in which this El Niño differed from previous major events in 1982/83 and 1997/98. The west-central Pacific subsurface and surface temperature anomalies were much warmer, while the eastern Pacific was comparatively cooler. As expected during El Niño, the trade winds were 
weaker, but not as weak during the last half of 2015 as during previous significant events. Related to this, the pressure differences across the tropical Pacific, as measured by the two Southern Oscillation indices, suggest the 2015/16 El Niño had less amplitude relative to the other events. The two OLR indices were both among the top three going back to 1979 but lagged the other two events in the eastern Pacific.

In some aspects, the operational model forecasts for the Niño-3.4 index were among the most skillful going back to at least 2002. However, this should not suggest complacency as seen during the borderline $\mathrm{El}$ Niño-neutral situation during 2014/15 when the dynamical models, in particular, largely overestimated the degree of warming. The longest-lead predictions in the dynamical, intermediate, and statistical models contain relatively large errors $\left(0.5^{\circ} \mathrm{C}\right.$ past lead- 4$)$, which make predictions of ENSO strength an ongoing challenge. Also, the ensemble average of the multimodel ensemble lagged the initial increases in Niño-3.4 during early 2015, especially for the statistical models, and underpredicted strength beyond the more immediate leads. Statistical models appear to be hampered by their inability to respond to submonthly factors that portend ENSO growth, though this may have paradoxically been to their advantage during 2014. While forecast improvements should be sought, an important challenge is to communicate that a portion of the forecast uncertainty is irreducible: there will always be error in the initial conditions, boundary forcing, and through the use of imperfect models.

Given the historical stature of the 2015/16 El Niño, it is clear that it will be an event that will be vigorously dissected. From an operational perspective, however, there are a couple of areas worth examining further. One fundamental challenge is to better understand the influence of trends in the real-time observational data. The WMO recommends that the most recent 30-yr base period be used to define anomalies [currently, 1981-2010; Arguez et al. (2012)], but it is likely that some part of the ENSO indices is not related purely to ENSO dynamics, but climate change and warming trends. So, how do we best quantify the portion of the anomalies related to ENSO versus the portion related to decadal, multidecadal, or secular variability? And how important is it to diagnose the role of trends when it comes to El Niño monitoring and prediction on a monthly or seasonal basis? For example, what are the consequences of $\mathrm{a}+2.3^{\circ} \mathrm{C}$ seasonal Niño-3.4 index value that is revised to $+2.1^{\circ} \mathrm{C}$ after trends are removed? Overall, how substantial is the effect of longterm variability on seasonal ENSO characteristics, dynamics, and predictability?
While our scientific understanding of climate change and its consequences has progressed markedly since $1997 / 98$, there are still challenges to quantifying and communicating its role on the shorter time scales. While the statistical decomposition in the previous section on global anomalies during DJF is offered as a first estimate, there are certainly other methods of extracting the role of various components of the climate system (e.g., Bonfils et al. 2015). Given the tremendous interest from the public to understand the drivers of recent climate anomalies, it remains worthwhile to fine-tune methods and test their applicability to a real-time environment.

The 2015/16 event was the first major " $24-7$ El Niño" coming within a vastly different media setting, with a fast and diverse network (e.g., mobile devices) that did not exist during the last major event of 1997/98. The forecast centers approached this in a variety of ways, using social media, videos and infographics, and blogs (e.g., ENSO blog: www .climate.gov/news-features/department/enso-blog) to provide additional information beyond that provided in routine operational assessments, typically issued at biweekly to monthly intervals. However, the constant coverage and frequent media updates remained surprising, as ENSO is a slow, seasonally evolving phenomenon that helps set the background flow and increases the chances for certain weather events to reoccur over certain areas but does not directly cause any weather event.

Thus, there was a visible disconnect between the demands of "here and now" coverage and the pace of useful updates that could be provided by the centers on ENSO. For example, while daily or weekly averaged data provide a useful snapshot of tendencies across the tropical Pacific Ocean, they are not currently designed to provide a long, continuous, stable record for historical comparison. Daily and weekly data can also be influenced by a variety of factors outside of ENSO [e.g., tropical cyclones, the Madden-Julian oscillation, and a number of other intraseasonal phenomena; Hendon and Glick (1997)]. Yet, despite these caveats, some users relied on these real-time data records to publicize frequent updates on the strength or rank of El Niño. Also, when certain precipitation impacts began to occur, these weather events were sometimes labeled as El Niño storms even though El Niño does not directly cause storms but, rather, sets the overall background for them.

Additionally, there were signs that the forecast for El Niño itself was conflated with the forecasts for its associated impacts. At the major national forecast centers, operations related to forecasting ENSO and operations related to creating outlooks of temperature 
and precipitation may be closely related, but they remain separate endeavors. ENSO is a leading predictor over certain countries and therefore strongly influences the seasonal climate outlook, but it is clearly not the only factor in the models considered by forecasters. The signal-to-noise ratio becomes smaller as one moves away from the tropical Pacific Ocean (e.g., Kumar et al.2000), and so, for most parts of the world, the confidence in an upcoming ENSO event is likely to be higher than the chance of its related impacts.

To clarify some of these service and communication issues, climate services aimed at bridging the provider-user gaps may be helpful. These can range from supporting studies of how users interpret and apply products, to buttressing science communication efforts, such as building easy-to-navigate, clearly described webpages supported by an authoritative social media presence. The role of "learning by doing" also cannot be overstated. With the occurrence of each El Niño event, there are opportunities to learn and apply those lessons to future events. The 2015/16 event was no different in this regard and will, hopefully, have provided many users with a greater appreciation of the probabilistic nature of impacts related to El Niño, which needs to be explicitly recognized and factored into their risk analysis and decision-making.

ACKNOWLEDGMENTS. We thank Leigh Zhang (NOAA/CPC) for updating several reanalysis datasets on our behalf. ML, EB, TD, and $\mathrm{AB}$ are grateful for support from the NOAA Climate Programs Office (CPO)/Climate. gov for the ENSO Blog. AB also acknowledges NOAA CPO/ MAPP Grant NA12OAR4310082. KT and KM acknowledge the PP068 program and colleagues at the ENFEN Committee. KT also appreciates the support of the U.S. Embassy in Peru, the Peruvian Embassy in the United States, and Min. J. M. Benites.

APPENDIX: VERIFICATION METRICS. In this paper, the anomaly correlation (AC) coefficient is computed as

$$
\mathrm{AC}=\frac{\overline{x^{\prime} y^{\prime}}}{\sigma_{x} \sigma_{y}},
$$

where $x$ and $y$ are the observational and forecast time series, primes denote anomalies from the time mean, the overbar indicates the average over time, and the sigmas are the standard deviation of $x$ and $y$. The numerator represents the covariance between $x$ and $y$.

The values associated with the AC lie between -1 and 1 and are dimensionless. Negative values indicate an inverse linear relations between $x$ and $y$, while positive values indicate a direct linear relations.
Values near zero indicate a poor fit between $x$ and $y$, and values at 1 or -1 reflect a perfect fit or match between the variability in $x$ and $y$.

The root-mean-square error (RMSE) is calculated as

$$
\mathrm{RMSE}=\sqrt{\frac{\sum(x-y)^{2}}{n}},
$$

where $n$ is the sample size. The RMSE is the square root of the average of the squares of the error, or the difference between $x$ and $y$. Larger RMSE values indicate larger differences either of the same sign (bias) or of both signs between the observational and forecast time series. Smaller RMSEs indicate smaller differences between the time series.

\section{REFERENCES}

Arguez, A., I. Durre, S. Applequist, R. S. Vose, M. F. Squires, X. Yin, R. R. Heim Jr., and T. W. Owen, 2012: NOAA's 1981-2010 U.S. climate normals: An overview. Bull. Amer. Meteor. Soc., 93, 1687-1697, doi:10.1175/BAMS-D-11-00197.1.

Barnston, A. G., M. Chelliah, and S. B. Goldenberg, 1997: Documentation of a highly ENSO-related SST region in the equatorial Pacific: Research note. Atmos.-Ocean, 35, 367-383, doi:10.1080/07055900 .1997.9649597.

—, M. K. Tippett, M. L. L'Heureux, S. Li, and D. G. DeWitt, 2012: Skill of real-time seasonal ENSO model predictions during 2002-11: Is our capability increasing? Bull. Amer. Meteor. Soc., 93, 631-651, doi:10.1175/BAMS-D-11-00111.1.

Bjerknes, J., 1969: Atmospheric teleconnections from the equatorial Pacific. Mon. Wea. Rev., 97, 163-172, doi:10.1175/1520-0493(1969)097<0163:ATFTEP >2 .3.CO;2.

Bonfils, C. J. W., B. D. Santer, T. J. Phillips, K. Marvel, L. R. Leung, C. Doutriaux, and A. Capotondi, 2015: Relative contributions of mean-state shifts and ENSO-driven variability to precipitation changes in a warming climate. J. Climate, 28, 9997-10013, doi:10.1175/JCLI-D-15-0341.1.

Butler, A. H., D. W. J. Thompson, and R. Heikes, 2010: The steady-state atmospheric circulation response to climate change-like thermal forcings in a simple general circulation model. J. Climate, 23, 3474-3496, doi:10.1175/2010JCLI3228.1.

Capotondi, A., and Coauthors, 2015: Understanding ENSO diversity. Bull. Amer. Meteor. Soc., 96, 921-938, doi:10.1175/BAMS-D-13-00117.1.

Chen, M., P. Xie, J. E. Janowiak, and P. A. Arkin, 2002: Global land precipitation: A 50-yr monthly analysis based on gauge observations. J. Hydrometeor., 3, 
249-266, doi:10.1175/1525-7541(2002)003<0249:GL $\mathrm{PAYM}>2.0 . \mathrm{CO} ; 2$.

Chiodi, A. M., and D. E. Harrison, 2013: El Niño impacts on seasonal U.S. atmospheric circulation, temperature, and precipitation anomalies: The OLR-event perspective. J. Climate, 26, 822-837, doi:10.1175 /JCLI-D-12-00097.1.

Dee, D. P., and Coauthors, 2011: The ERA-Interim reanalysis: Configuration and performance of the data assimilation system. Quart. J. Roy. Meteor. Soc., 137, 553-597, doi:10.1002/qj.828.

DelSole, T., J. Nattala, and M. K. Tippett, 2014: Skill improvement from increased ensemble size and model diversity. Geophys. Res. Lett., 41, 7331-7342, doi:10.1002/2014GL060133.

Fan, Y., and H. Van den Dool, 2008: A global monthly land surface air temperature analysis for 1948-present. J. Geophys. Res., 113, D01103, doi:10.1029/2007JD008470.

Goddard, L., D. G. DeWitt, and R. W. Reynolds, 2009: Practical implications of uncertainty in observed SSTs. Geophys. Res. Lett., 36, L09710, doi:10.1029/2009GL037703.

Halpert, M. S., and C. F. Ropelewski, 1992: Surface temperature patterns associated with the Southern Oscillation. J. Climate, 5, 577-593, doi:10.1175/1520 -0442(1992)005<0577:STPAWT>2.0.CO;2.

Hendon, H. H., and J. Glick, 1997: Intraseasonal airsea interaction in the tropical Indian and Pacific Oceans. J. Climate, 10, 647-661, doi:10.1175/15200442(1997)010<0647:IASIIT>2.0.CO;2.

—, D. W. J. Thompson, and M. C. Wheeler, 2007: Australian rainfall and surface temperature variations associated with the Southern Hemisphere annular mode. J. Climate, 20, 2452-2467, doi:10.1175 /JCLI4134.1.

Horel, J. D., and J. M. Wallace, 1981: Planetary-scale atmospheric phenomena associated with the Southern Oscillation. Mon. Wea. Rev., 109, 813-829, doi:10.1175/15200493(1981)109<0813:PSAPAW>2.0.CO;2.

Hu, Z.-Z., A. Kumar, H.-L. Ren, H. Wang, M. L. Heureux, and F.-F. Jin, 2013: Weakened interannual variability in the tropical Pacific Ocean since 2000. J. Climate, 26, 2601-2613, doi:10.1175/JCLI-D-12-00265.1.

Huang, B., W. Wang, C. Liu, V. Banzon, H.-M. Zhang, and J. Lawrimore, 2015a: Bias adjustment of AVHRR SST and its impacts on two SST analyses. J. Atmos. Oceanic Technol., 32, 372-387, doi:10.1175/JTECH -D-14-00121.1.

— , and Coauthors, 2015b: Extended Reconstructed Sea Surface Temperature version 4 (ERSST.v4). Part I: Upgrades and intercomparisons. J. Climate, 28, 911-930, doi:10.1175/JCLI-D-14-00006.1.
— - M. L'Heureux, Z.-Z. Hu, and H.-M. Zhang, 2016: Ranking the strongest ENSO events while incorporating SST uncertainty. Geophys. Res. Lett., 43, 9165-9172, doi:10.1002/2016GL070888.

Ishii, M., A. Shouji, S. Sugimoto, and T. Matsumoto, 2005: Objective analyses of sea-surface temperature and marine meteorological variables for the 20th century using ICOADS and the Kobe collection. Int. J. Climatol., 25, 865-879, doi:10.1002/joc.1169.

Kalnay, E., and Coauthors, 1996: The NCEP/NCAR 40 Year Reanalysis Project. Bull. Amer. Meteor. Soc., 77, 437-471, doi:10.1175/1520-0477(1996)077<0437:TN YRP $>2.0 . C O ; 2$.

Kanamitsu, M., W. Ebisuzaki, J. Woollen, S.-K. Yang, J. J. Hnilo, M. Fiorino, and G. L. Potter, 2002: NCEPDOE AMIP-II reanalysis (R-2). Bull. Amer. Meteor. Soc., 83, 1631-1643, doi:10.1175/BAMS-83-11-1631.

Kirtman, B. P., and Coauthors, 2014: The North American Multimodel Ensemble: Phase-1 seasonal-tointerannual prediction; phase-2 toward developing intraseasonal prediction. Bull. Amer. Meteor. Soc., 95, 585-601, doi:10.1175/BAMS-D-12-00050.1.

Kobayashi, S., and Coauthors, 2015: The JRA-55 reanalysis: General specifications and basic characteristics. J. Meteor. Soc. Japan, 93, 5-48, doi:10.2151 /jmsj.2015-001.

Kumar, A., and Z.-Z. Hu, 2014: How variable is the uncertainty in ENSO sea surface temperature prediction? J. Climate, 27, 2779-2788, doi:10.1175 /JCLI-D-13-00576.1.

- A. G. Barnston, P. Peng, M. P. Hoerling, and L. Goddard, 2000: Changes in the spread of the variability of the seasonal mean atmospheric states associated with ENSO. J. Climate, 13, 3139-3151, doi:10.1175/1520 -0442(2000)013<3139:CITSOT>2.0.CO;2.

Lee, H.-T., A. Gruber, R. G. Ellingson, and I. Laszlo, 2007: Development of the HIRS outgoing longwave radiation climate dataset. J. Atmos. Oceanic Technol., 24, 2029-2047, doi:10.1175/2007JTECHA989.1.

Lee, T., and M. J. McPhaden, 2010: Increasing intensity of El Niño in the central-equatorial Pacific. Geophys. Res. Lett., 37, L14603, doi:10.1029/2010GL044007.

LHeureux, M. L., and D. W. J. Thompson, 2006: Observed relationships between the El Niño-Southern Oscillation and the extratropical zonal-mean circulation. J. Climate, 19, 276-287, doi:10.1175/JCLI3617.1.

— D. C. Collins, and Z.-Z. Hu, 2013: Linear trends in sea surface temperature of the tropical Pacific Ocean and implications for the El Niño-Southern Oscillation. Climate Dyn., 40, 1223-1236, doi:10.1007 /s00382-012-1331-2.

—, M. K. Tippett, and A. G. Barnston, 2015: Characterizing ENSO coupled variability and its impact 
on North American seasonal precipitation and temperature. J. Climate, 28, 4231-4245, doi:10.1175 /JCLI-D-14-00508.1.

Liebmann, B., and C. A. Smith, 1996: Description of a complete (interpolated) outgoing longwave radiation dataset. Bull. Amer. Meteor. Soc., 77, 1275-1277.

Lim, E.-P., H. H. Hendon, J. M. Arblaster, C. Chung, A. F. Moise, P. Hope, G. Young, and M. Zhao, 2016: Interaction of the recent 50 year SST trend and La Niña 2010: Amplification of the Southern Annular Mode and Australian springtime rainfall. Climate Dyn., 47, 2273-2291, doi:10.1007/s00382-015-2963-9.

Limpasuvan, V., and D. L. Hartmann, 2000: Wavemaintained annular modes of climate variability. J. Climate, 13, 4414-4429, doi:10.1175/1520 $-0442(2000) 013<4414$ :WMAMOC $>2.0 . C O ; 2$.

McPhaden, M. J., 1999: Genesis and evolution of the 1997-98 El Niño. Science, 283, 950-954, doi:10.1126/ science.283.5404.950.

_ 2015: Playing hide and seek with El Niño. Nat. Climate Change, 5, 791-795, doi:10.1038/nclimate2775.

—, A. Busalacchi, and D. Anderson, 2010: A TOGA retrospective. Oceanography, 23, 86-103, doi:10.5670 /oceanog.2010.26.

Murphy, B. F., and B. Timbal, 2008: A review of recent climate variability and climate change in southeastern Australia. Int. J. Climatol., 28, 859-879, doi:10.1002/joc.1627.

Palmer, T. N., and Coauthors, 2004: Development of a European Multimodel Ensemble System for Seasonal-toInterannual Prediction (DEMETER). Bull. Amer. $\mathrm{Me}$ teor. Soc., 85, 853-872, doi:10.1175/BAMS-85-6-853.

Rayner, N. A., D. E. Parker, E. B. Horton, C. K. Folland, L. V. Alexander, D. P. Rowell, E. C. Kent, and A. Kaplan, 2003: Global analyses of sea surface temperature, sea ice, and night marine air temperature since the late nineteenth century. J. Geophys. Res., 108, 4407, doi:10.1029/2002JD002670.

Reynolds, R. W., N. A. Rayner, T. M. Smith, D. C. Stokes, and W. Wang, 2002: An improved in situ and satellite SST analysis for climate. J. Climate, 15, 1609-1625, doi:10.1175/1520-0442(2002)015<1609:AIISAS >2. $0 . \mathrm{CO} ; 2$.

— T. M. Smith, C. Liu, D. B. Chelton, K. S. Casey, and M. G. Schlax, 2007: Daily high-resolution-blended analyses for sea surface temperature. J. Climate, 20, 5473-5496, doi:10.1175/2007JCLI1824.1.

Rienecker, M. M., and Coauthors, 2011: MERRA: NASA's Modern-Era Retrospective Analysis for
Research and Applications. J. Climate, 24, 36243648, doi:10.1175/JCLI-D-11-00015.1.

Roemmich, D., and J. Gilson, 2009: The 2004-2008 mean and annual cycle of temperature, salinity, and steric height in the global ocean from the Argo program. Prog. Oceanogr., 82, 81-100, doi:10.1016/j .pocean.2009.03.004.

Ropelewski, C. F., and M. S. Halpert, 1987: Global and regional scale precipitation patterns associated with the El Niño/Southern Oscillation. Mon. Wea. Rev., 115, 1606-1626, doi:10.1175/1520 -0493(1987)115<1606:GARSPP>2.0.CO;2.

Saha, S., and Coauthors, 2010: The NCEP Climate Forecast System Reanalysis. Bull. Amer. Meteor. Soc., 91, 1015-1057, doi:10.1175/2010BAMS3001.1.

Shi, W., N. Schaller, D. MacLeod, T. N. Palmer, and A. Weisheimer, 2015: Impact of hindcast length on estimates of seasonal climate predictability. Geophys. Res. Lett., 42, 1554-1559, doi:10.1002/2014GL062829.

Smith, T. M., R. W. Reynolds, T. C. Peterson, and J. Lawrimore, 2008: Improvements to NOAA's historical merged land-ocean surface temperature analysis (1880-2006). J. Climate, 21, 2283-2296, doi:10.1175/2007JCLI2100.1.

Takahashi, K., 2004: The atmospheric circulation associated with extreme rainfall events in Piura, Peru, during the 1997-1998 and 2002 El Niño events. Ann. Geophys., 22, 3917-3926, doi:10.5194 langeo-22-3917-2004.

— linear El Niño regimes. Climate Dyn., 46, 1627-1645, doi:10.1007/s00382-015-2665-3.

—, A. Montecinos, K. Goubanova, and B. Dewitte, 2011: ENSO regimes: Reinterpreting the canonical and Modoki El Niño. Geophys. Res. Lett., 38, L10704, doi:10.1029/2011GL047364.

Thomas, J. L., D. W. Waugh, and A. Gnanadesikan, 2015: Southern Hemisphere extratropical circulation: Recent trends and natural variability. Geophys. Res. Lett., 42, 5508-5515, doi:10.1002/2015GL064521.

Vecchi, G. A., and D. E. Harrison, 2006: The termination of the 1997-1998 El Niño. Part I: Mechanisms of oceanic change. J. Climate, 19, 2633-2646, doi:10.1175 /JCLI3776.1.

—, A. T. Wittenberg, and A. Rosati, 2006: Reassessing the role of stochastic forcing in the 1997-1998 El Niño. Geophys. Res. Lett., 33, L01706, doi:10.1029/2005GL024738. 